\title{
Human endotrophin as a driver of malignant tumor growth
}

Dawei Bu, ${ }^{1}$ Clair Crewe, ${ }^{1}$ Christine M. Kusminski, ${ }^{1}$ Ruth Gordillo, ${ }^{1}$ Alexandra L. Ghaben, ${ }^{1}$ Min Kim, ${ }^{2}$ Jiyoung Park, ${ }^{2}$ Hui Deng, ${ }^{3}$ Wei Xiong, ${ }^{3}$ Xiao-Zheng Liu, ${ }^{4}$ Per Eystein Lønning, ${ }^{5}$ Nils Halberg, ${ }^{4}$ Adan Rios, ${ }^{3,6}$ Yujun Chang, ${ }^{7}$ Anneliese Gonzalez, ${ }^{6}$ Ningyan Zhang, ${ }^{3}$ Zhiqiang An, ${ }^{3}$ and Philipp E. Scherer ${ }^{1}$

${ }^{1}$ Touchstone Diabetes Center, Departments of Internal Medicine and Simmons Cancer Center, University of Texas Southwestern Medical Center, Dallas, Texas, USA. ${ }^{2}$ Department of Biological Sciences, School of Life Sciences, Ulsan National Institute of Science and Technology, Ulsan, South Korea. ${ }^{3}$ Texas Therapeutics Institute, Brown Foundation Institute of Molecular Medicine, University of Texas Health Science Center at Houston, Houston, Texas, USA. ${ }^{4}$ Department of Biomedicine, University of Bergen, Bergen, Norway. ${ }^{5}$ Department of Clinical Science, Faculty of Medicine, University of Bergen, and Department of Oncology, Haukeland University Hospital, Bergen, Norway. ${ }^{6}$ Division of Oncology, Department of Internal Medicine, University of Texas Health Science Center at Houston, Houston, Texas, USA. ${ }^{7}$ Panamab, Houston, Texas, USA.

We have previously reported that the carboxy-terminal proteolytic cleavage product of the COL6 33 chain that we refer to as "endotrophin" has potent effects on transformed mammary ductal epithelial cells in rodents. Endotrophin (ETP) is abundantly expressed in adipose tissue. It is a chemoattractant for macrophages, exerts effects on endothelial cells and through epithelialmesenchymal transition (EMT) enhances progression of tumor cells. In a recombinant form, human endotrophin exerts similar effects on human macrophages and endothelial cells as its rodent counterpart. It enhances EMT in human breast cancer cells and upon overexpression in tumor cells, the cells become chemoresistant. Here, we report the identification of endotrophin from human plasma. It is circulating at higher levels in breast cancer patients. We have developed neutralizing monoclonal antibodies against human endotrophin and provide evidence for the effectiveness of these antibodies to curb tumor growth and enhance chemosensitivity in a nude mouse model carrying human tumor cell lesions. Combined, the data validate endotrophin as a viable target for anti-tumor therapy for human breast cancer and opens the possibility for further use of these new reagents for anti-fibrotic approaches in liver, kidney, bone marrow and adipose tissue.

Conflict of interest: This study was partially funded by a grant from PanaMab. YC is an employee of PanaMab. AR, ZA, and PS are cofounders of PanaMab.

Copyright: (c) 2019 American Society for Clinical Investigation

Submitted: September 24, 2018 Accepted: March 14, 2019 Published: May 2, 2019.

Reference information: /CI Insight. 2019;4(9):e125094. https://doi. org/10.1172/jici.insight.125094

\section{Introduction}

Obesity potently enhances the risk for tumor development (1). While this holds true for almost all cancer types, particular subsets of cancers are more affected than others. These include pancreatic, liver, colon and endometrial, as well as postmenopausal breast cancer (2). The underlying mechanistic connections however, remain only at an early stage of investigation. In breast cancer, it is clear that stromal adipocytes are involved in tumor progression, as the transformed ductal epithelial cells break through the basal lamina, and start their growth in the adipocyte-rich environment of the mammary gland stroma $(3,4)$.

Previously, we identified a carboxy-terminal cleavage product of collagen VI $\alpha 3$, which we refer to as endotrophin, as a critical player of tumor progression in the murine mammary gland $(5,6)$. We have established important contributions of endotrophin towards tumor progression, metastatic growth and fibrosis, through a series of experimental approaches based on both genetic gain- and loss-of-function models, as well as neutralizing antibody treatment $(5,6)$. While we reported an upregulation of endotrophin using histological analysis in a host of human tumor samples, it remained unclear whether endotrophin is an effective growth stimulator for human breast cancer cells as well (7). Here, we examined the direct effects of human endotrophin on human macrophages, endothelial cells, and human breast cancer cells. We generated monoclonal antibodies against human endotrophin, and subsequently, tested the effectiveness of these antibodies in vitro and in vivo as tools to curb tumor growth and enhance the susceptibility to cisplatin. We conclude that the initial observations established for 
the physiological effects of endotrophin in rodent cells (8) translate very effectively to the cellular physiology of human cells.

\section{Results}

Endotrophin can be isolated from human plasma. To date, we have accumulated a large body of evidence for a broad array of physiological responses to endotrophin in rodents (7-10). We initiated a series of experiments to determine whether a similar set of responses occur in humans. Thus far, we have not defined the exact nature of locally acting and circulating endotrophin. We therefore raised a monoclonal antiserum against the C-terminal region of what we predicted to be human endotrophin. We utilized these antibodies (ETPmAb4 - see below) to immunoprecipitate endotrophin from human plasma. Anti-human endotrophin antibodies were immobilized on an agarose resin by covalent thioester bonding, in order to immunoprecipitate endotrophin from human plasma from a healthy individual from a commercial source (Figure 1A). We resolved the immunoprecipitate by SDS-PAGE and excised a gel region corresponding to the estimated molecular weight of endotrophin $(\sim 10-15 \mathrm{kDa})$ for subsequent protein sequencing. This unambiguously establishes the presence of endotrophin in circulation in humans, and further defines endotrophin as a peptide of 91 amino acids. Consistent with this molecular mass, there are two nearby predicted MMP14 cleavage sites (Figure 1B).

As proof-of-principle, we combined these antibodies with a rabbit monoclonal antibody against human endotrophin and developed an ELISA assay (Supplemental Figure 1, A-D; supplemental material available online with this article; https://doi.org/10.1172/jci.insight.125094DS1); we subsequently used this assay to measure endotrophin in a cohort of breast cancer patients. While the size of this cohort does not allow us to make any significant statements with regards to the prevalence of endotrophin upregulation in human breast cancer patients with different subtypes, interestingly, we observed a significant upregulation of endotrophin in breast cancer patients compared to cancer-free patients (Figure 1C). Consistent with the circulating levels of endotrophin, the gene expression levels of collagen $6 \alpha 3$ (Col6a3) in primary breast tumors are also increased, when compared with patient-matched non-tumor tissues (Figure 1D). Of note, there was no statistically significant difference in body mass index (BMI) or in the age between the two groups (data not shown). Furthermore, in primary tumors, Col6 $\alpha 3$ expression levels are significantly negatively correlated with survival in breast cancer patients treated with chemotherapy. This suggests that Col6 $\alpha 3$ and its cleavage product endotrophin, plays an important contributory role to promote tumor progression in breast cancer patients (Figure 1E). This relationship with reduced survival rate is maintained effectively in pre-menopausal and post-menopausal breast cancers, and is also independent of estrogen receptor status of the tumor cells (Supplemental Figure 1, E-H). Based on these results, recombinant endotrophin was expressed in HEK293 cells, and the protein was used to immunize rabbits for endotrophin targeting monoclonal antibodies.

Effects of human endotrophin on human cells in vitro. We subsequently wanted to assess whether some of the initial effects described for murine endotrophin, would translate for human endotrophin. To achieve this objective, we utilized the human breast cancer cell line T47D (an ER positive cell line) (11), to examine whether human endotrophin exerts a similar effect on human cancer cells as it does in rodents; whereby the latter effectively triggers epithelial-to-mesenchymal transition (EMT) (12). After examining the transcriptional alterations that occur in response to endotrophin exposure, we indeed observed a significant two-fold upregulation of the EMT markers Twist and Snail, with a significant but less profound increase in N-Cadherin (Cdh2) (13); this was paralleled with a marked downregulation in epithelial cell marker E-cadherin (Cdh1) (Figure 2A). In conjunction with this, we also utilized primary human mesothelial cells to probe for the same effects (14). Consistent with what we observed for T47D cells, we also observed an upregulation of mesenchymal cell markers, along with a downregulation in Cdh1 gene expression levels, in an endotrophin dose-dependent fashion (Figure 2B). These findings were further reproduced in vitro with a number of additional human breast cancer cell lines, such as ZR-75-1 cells (ER positive), MCF-7 cells (ER positive) as well as MDA-MB-231 cells (ER negative) (Supplemental Figure 2, A-C).

With these effects on epithelial cells validated, we further wanted to probe the impact of endotrophin on human endothelial cells. For this purpose, we utilized a preparation of human umbilical vein endothelial cells (HUVECs) (15), grown in a dish to near confluence. A gap was then introduced across the plate by removing cells with a cell scraper, indicated by the dashed line (16). Using this scratch assay, we examined whether endotrophin in the tissue culture supernatant, could enhance the migration of HUVECs into the open space. This was the case, as judged by the quantitation of the number of cells occupying the gap, as a function of the added endotrophin concentration. In the pres- 
A

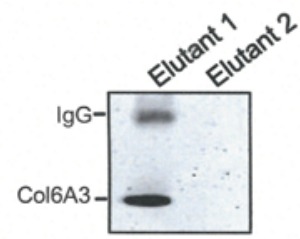

B

Human: PPPPQPAARSASSSTINLMVS TEPLALTETDICKLPKDEGTCRDFILKWYYDPNTKSCARFWYGGCGGNENKFGSQKECEKVCAPVLAKPGVISVMGT Mouse: PPPLQAAHRASSSTINLMVN TEPLFLTKTDICKLSRDAGTCVDFKLLWHYDLESKSCKRFWYGGCGGNENRFHSQEECEKMCSPDLLV

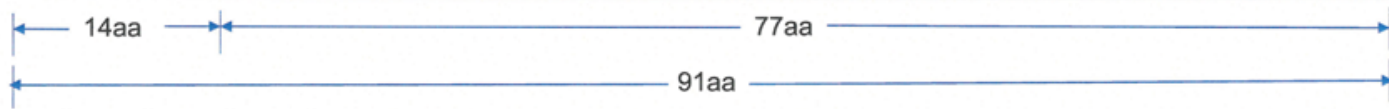

C

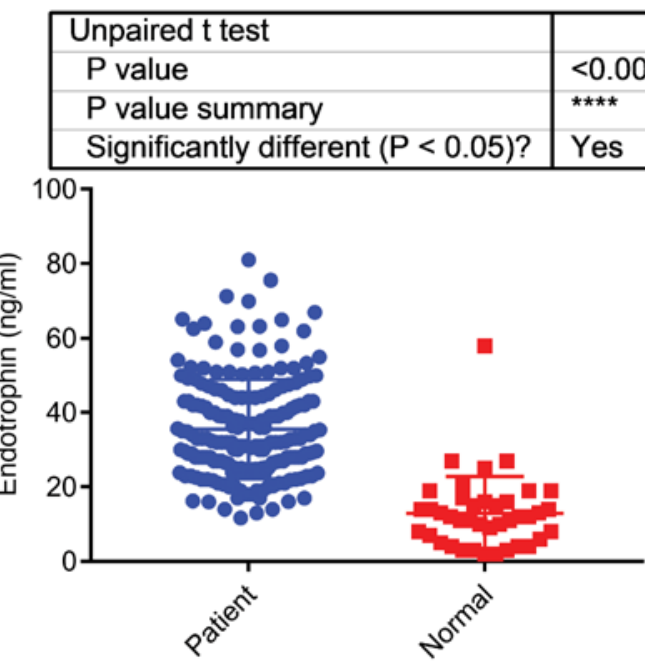

E

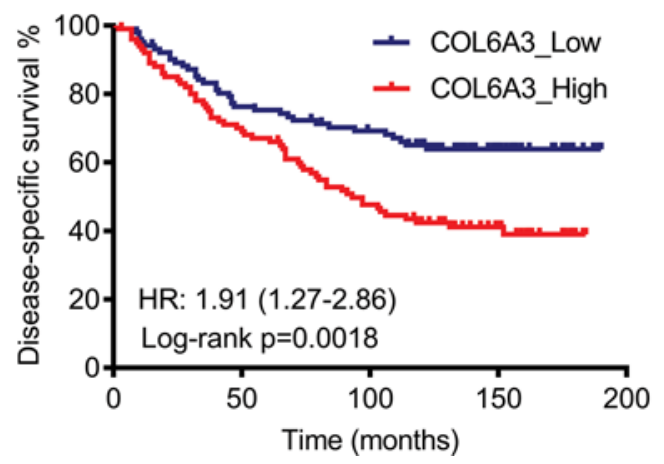

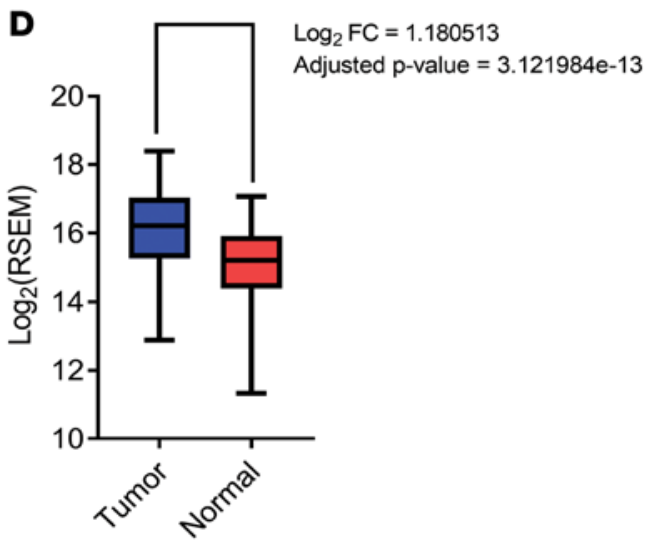

Figure 1. Identification of plasma endotrophin and elevated endotrophin levels in breast cancer patients. (A) Western blot analysis of immunoprecipitated endotrophin (Col6A3) from human plasma. (B) The C-terminal endotrophin sequence in mice and humans. The sequence highlighted in blue denotes the portion used to produce recombinant endotrophin. Mass Spectroscopy sequencing of the human endotrophin elutant identified an additional $14 \mathrm{~N}$-terminal amino acids (red highlight). The arrows indicate the MMP consensus sites. (C) Higher levels of plasma endotrophin collected from peripheral blood in breast cancer patients $(n=$ $195)$ than that in normal donors $(n=40)$. (D) Enhanced gene expression of collagen $6 \alpha 3$ (Col6 $\alpha 3$ ) in tumor tissue, when compared to healthy tissue collected from tumor distal sites. Data from 111 breast cancer patients from data generated by the TCGA Research Network (E) Kaplan-Meier survival curves of breast cancer patients stratified by the mRNA expression level of Col6a3. Data generated by the TCGA Research Network $(n=203)$. Neither age nor BMI are statistically different between the COL6A3 high/low expression groups.

ence of endotrophin in the medium, there is a significant enhancement in the migration of tumor cells into the existing gap as a function of increasing endotrophin concentrations (Figure 2C). Just like for the analysis of the endotrophin-induced EMT, we expanded these scratch assays to breast cancer cells lines, with MCF-7 cells, ZR-75-1 cells, MDA-MB-453 cells (ER negative) and MDA-MB-231 cells (ER negative) with results very comparable to the response seen for HUVEC cells (Supplemental Figure 2, D-G). In addition, we wanted to corroborate these findings in a trans-well assay with HUVECs seeded into the top chamber, and an assessment of the migratory behavior of these cells to the lower chamber, as a function of the presence or absence of recombinant endotrophin (17). The presence of endotrophin in the lower chamber indeed significantly enhanced the trans-well migratory behavior of 
A

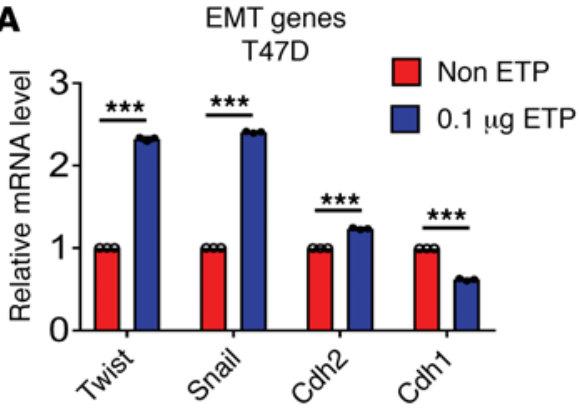

C

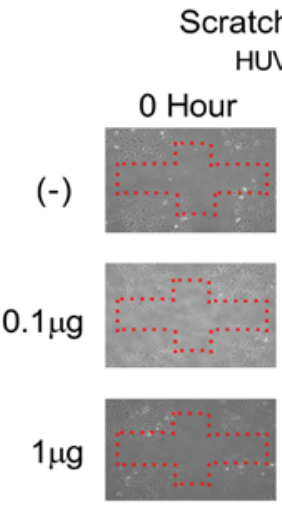

D

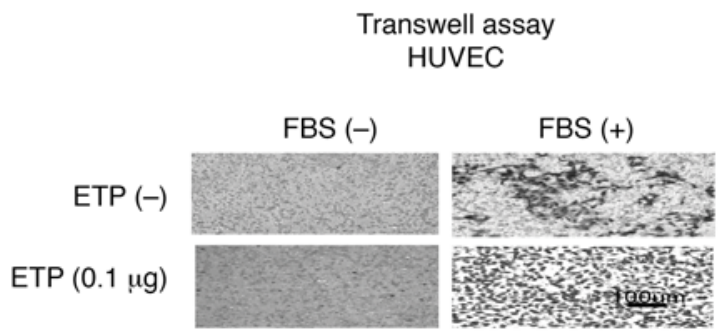

ranswell assay

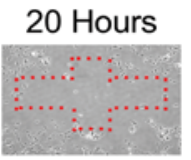

10óử

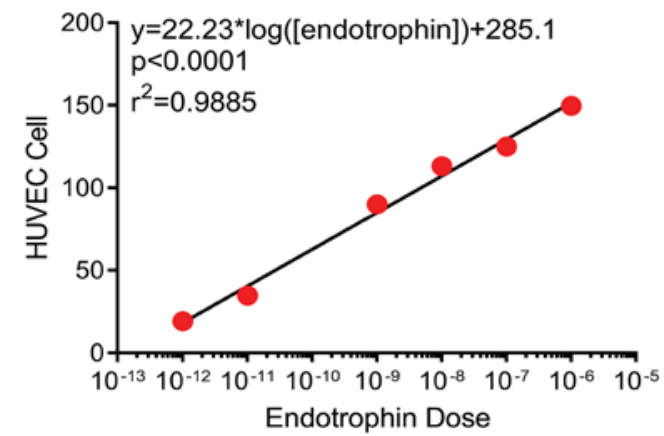

B

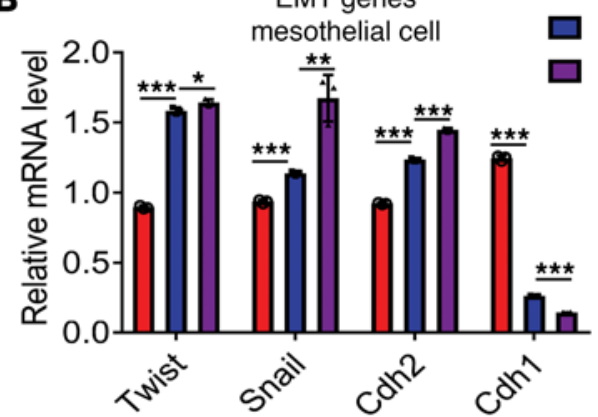

Endotrophin Dose

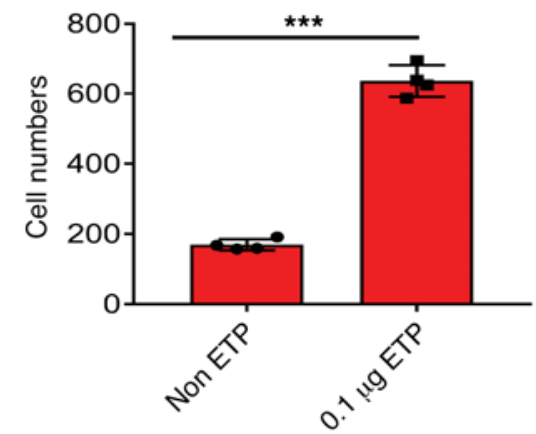

Non ETP

$0.1 \mu \mathrm{g}$ ETP

$1 \mu \mathrm{g}$ ETP
E

$$
\text { Tube formation }
$$

HUVEC

$(-)$

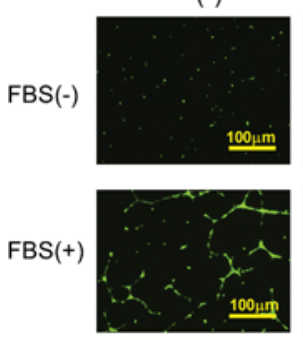

$0.1 \mu \mathrm{g}$
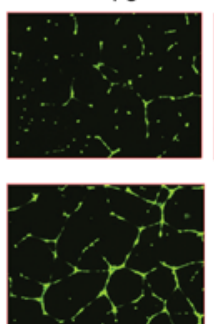

$1 \mu \mathrm{g}$
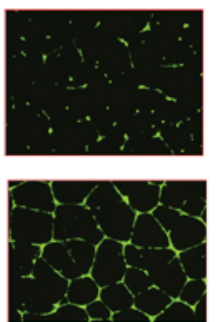

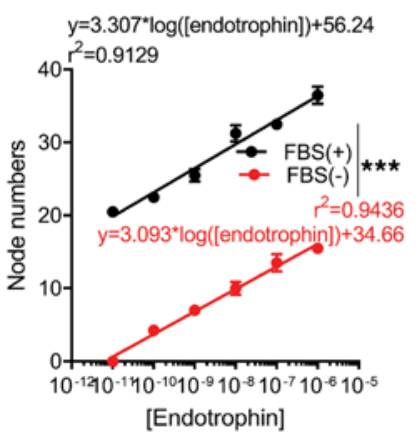

F Transwell assay

SC macrophage

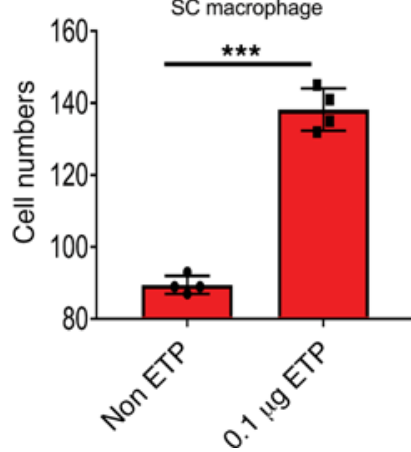

Figure 2. Effects of human endotrophin on human cells in vitro. (A) T47D breast cancer cells $\left(5 \times 10^{5}\right.$ cells) were plated into 6 -well plates and treated with endotrophin $(0.1 \mu \mathrm{g} / \mathrm{mL}) 3$ times (every other day). Total RNA was then extracted from each well. The EMT marker genes Twist, Snail, Cdh2, and Cdh1 were determined by qRT-PCR, then normalized to GAPDH. Mean \pm SEM, $n=3$. (B) Primary human mesothelial cells $\left(5 \times 10^{5}\right.$ cells $)$ were plated into a 6 -well plate and were treated with endotrophin $(0.1 \mu \mathrm{g} / \mathrm{mL}$ and $1 \mu \mathrm{g} / \mathrm{mL}) 3$ times (every other day). Total RNA was extracted from each well and EMT genes Twist, Snail, Cdh2, and Cdh1 were determined by qRT-PCR and normalized to GAPDH. Mean \pm SEM, $n=3$. (C) HUVEC cells (40,000 cells) were plated into 24-well plate. When the cells reached $90 \%$ confluence, the monolayer was scratched with a $1 \mathrm{~mL}$ pipette tip to create 2 perpendicular straight lines across the center of the well. Cells were then treated with increasing concentrations of endotrophin ( $10 \mathrm{pg} / \mathrm{mL}, 100 \mathrm{pg} / \mathrm{mL}, 1 \mathrm{ng} / \mathrm{mL}, 10 \mathrm{ng} / \mathrm{mL}, 0.1 \mu \mathrm{g} / \mathrm{mL}$, and $1 \mu \mathrm{g} / \mathrm{mL})$. Images were obtained using a Nikon Cool Scope microscope (Nikon) after a 20 hour incubation. Migrating cell numbers were evaluated using Imagej software. 
Statistical significance of the curve fit parameters was tested using the extra sum of squares $\mathrm{F}$ test with $P<0.05$ considered significant. Goodness of curve fit is described using $\mathrm{r}^{2}$. Mean \pm SEM, $n=4$. Scale bars: $100 \mu \mathrm{m}$. (D) HUVEC cells $\left(5 \times 10^{5}\right.$ cells) were plated at the top chamber in a trans-well plate. Endotrophin $(0.1 \mu \mathrm{g} / \mathrm{mL})$ was then added with or without $1 \%$ FBS in the lower chamber, then incubated for 16 hours. Images were then obtained on a Nikon Cool Scope microscope (Nikon) after a 16 hours incubation. Mean \pm SEM, $n=4$. Scale bars: $100 \mu m$ (E) HUVEC cells (40,000 cells) were plated into a gel-coated 24-well plate. Cells were then treated with endotrophin ( $10 \mathrm{pg} / \mathrm{mL}, 100 \mathrm{pg} / \mathrm{mL}, 1 \mathrm{ng} / \mathrm{mL}, 10 \mathrm{ng} / \mathrm{mL}, 0.1 \mu \mathrm{g} / \mathrm{mL}$, and $1 \mu \mathrm{g} / \mathrm{mL}$ ), with or without $1 \% \mathrm{FBS}$ for 16 hours. A cell-permeable dye, Calcein, was added for fluorescent monitoring of tube formation. Images were then obtained using a Nikon Cool Scope microscope (Nikon) after 16 hours. The statistical significance of the effect of FBS treatment on node number was tested by comparing the curve fits using a sum of squares $\mathrm{F}$ test. Goodness of fit of each individual regression is described using $\mathrm{r}^{2}$. Mean $\pm \mathrm{SEM}, n=3$. Scale bars: $100 \mu \mathrm{m}$ (F) SC macrophage cells ( 50,000 cells) were seeded at the top of the chamber. Endotrophin $(0.1 \mu \mathrm{g} / \mathrm{mL})$ was added with $1 \%$ FBS in the lower chamber and incubated for 2 hours. Migrated cells were then counted after 2 hours. Mean \pm SEM, $n=4$. In all cases, data was represented as mean \pm SEM and statistical significance (*** $P<0.0001)$ was calculated using unpaired, 2-tailed $t$-test w/Holm-Sidak correction for multiple comparisons.

the HUVECs (Figure 2D). A similar chemoattractant activity is observed for all breast cancer cells tested (MCF-7, ZR-75-1, MDA-MB-453 and MDA-MB-231), with a strong affinity of cells to migrate along an endotrophin gradient (Supplemental Figure 2, H-K).

We subsequently performed an additional test with the HUVEC cells. Endothelial cells, when exposed to an appropriate stimulus, form structures in vitro that reflect the pro-angiogenic properties of the system in vivo. These tube formation assays can also be performed with HUVECs (18). Compared to the absence of serum, or the presence of serum containing low levels of endogenous endotrophin, serum supplemented with exogenous recombinant endotrophin shows a potent stimulatory effect on tube formation in a dose-dependent fashion (Figure 2E) in strong support of a pro-angiogenic role of endotrophin in vivo.

In addition to effects on endothelial and breast cancer cells, we have observed a chemoattractant effect of endotrophin on monocytes and macrophages that are recruited to tumor lesions in mice. We therefore assayed the chemoattractant properties of human endotrophin on human macrophages. Similar to the approach with HUVECs, we seeded human SC macrophages (19) in the top chamber, and assayed the migratory procedure of the macrophages across the well towards the bottom chamber. The presence of recombinant endotrophin in the bottom chamber strongly stimulated the migration the SC macrophages towards endotrophin (Figure 2F).

Generation and screening of anti-human endotrophin antibodies. Using the recombinant endotrophin employed for the assays described above, we raised monoclonal antibodies in rabbits. We examined a panel of 132 monoclonal antibodies, not only for immune-crossreactivity against human endotrophin, but also for their ability to neutralize endotrophin action. To achieve this, we established an assay with the human breast cancer cell line, MCF-7 (20). These cells express very low levels of endotrophin, and as such, this renders them susceptible to the actions of cisplatin. The presence of recombinant endotrophin results in an increased resistance to cisplatin. The screening assay we established aimed to examine the effectiveness of the antibodies to neutralize endotrophin action, thereby making the cells susceptible again to cisplatin-induced cell death (Supplemental Figure 3). Additional screening of a subset of antibodies was performed with trans-well assays, with SC macrophage cells migrating towards endotrophin; this helped to corroborate the initial findings (Supplemental Figure 4). Based on these screening experiments, we selected one rabbit monoclonal antibody which we named ETPmAb4 for further study. We repeated these assays with ETPmAb4 and demonstrated that ETPmAb4 completely neutralizes endotrophin-mediated MCF-7 cell survival (Figure 3A, left). Furthermore, this effect whereby MCF-7 cells exposed to endotrophin become cisplatin resistant, treatment with antibody ETPmAb4 forced the cells to become susceptible to cisplatin, in a dose-dependent manner (Figure 3A, right). We generated MCF-7 cells that were stably transfected with a control vector, or isolated a MCF-7 clone that was transfected with a plasmid, enabling the expression of endotrophin under the control of a signal sequence, which effectively enabled these cells to secrete endotrophin into the tissue culture supernatant (Figure 3B). Of note, is the fact that MCF-7 cells express very low levels of endogenous ColVI $\alpha 3$ compared to other breast cancer cell lines (Figure 3C). Not only have we previously shown that MCF-7 cells are responsive to endotrophin as judged by the effective induction of the EMT process by exogenously added endotrophin (Supplemental Figure 2B), we see a constitutive shift towards enhanced EMT marker expression in MCF-7 cells stably transfected with endotrophin (Figure 3D). Using these stable endotrophin expressing MCF-7 transfectants, we also seeded macrophages in the top chamber of a trans-well plate, and endotrophin overexpressing MCF-7 cells were seeded at the bottom. The inclusion of ETPmAb4 along with the MCF-7 overexpressing cells, effectively prevented the migration of the SC macrophages into the bottom chamber, and the neutralizing activity of ETPmAb4 was dose-responsive (Figure 3E). 
A

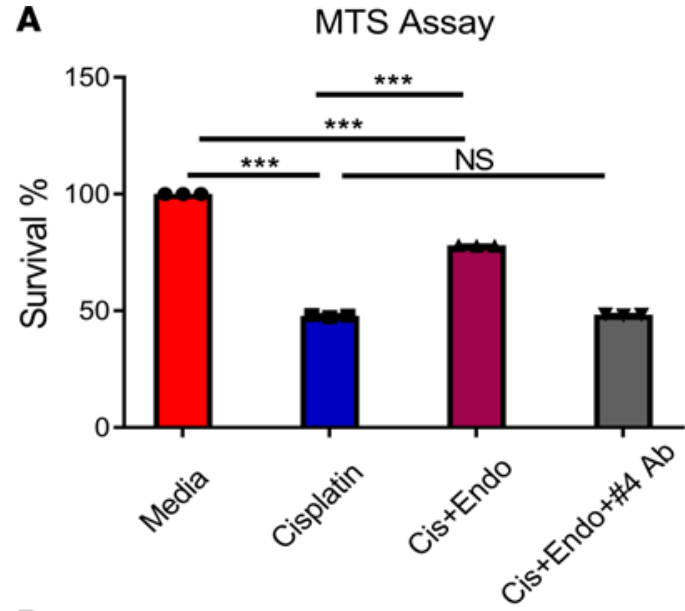

B

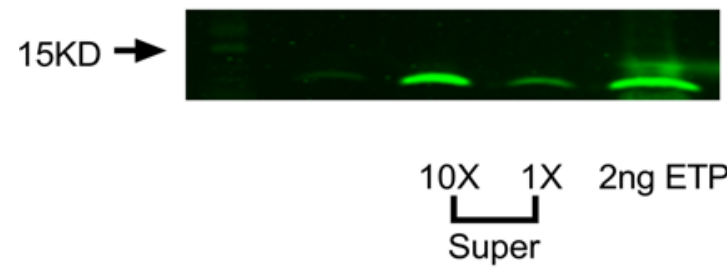

D

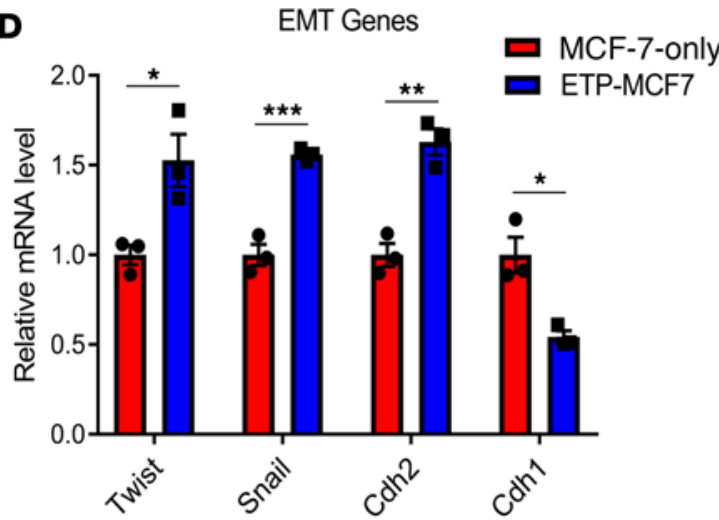

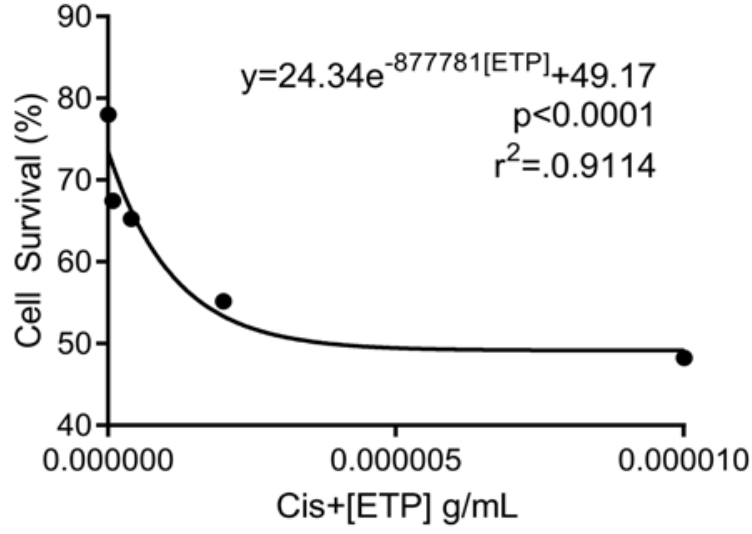

C

ColVla3 expression
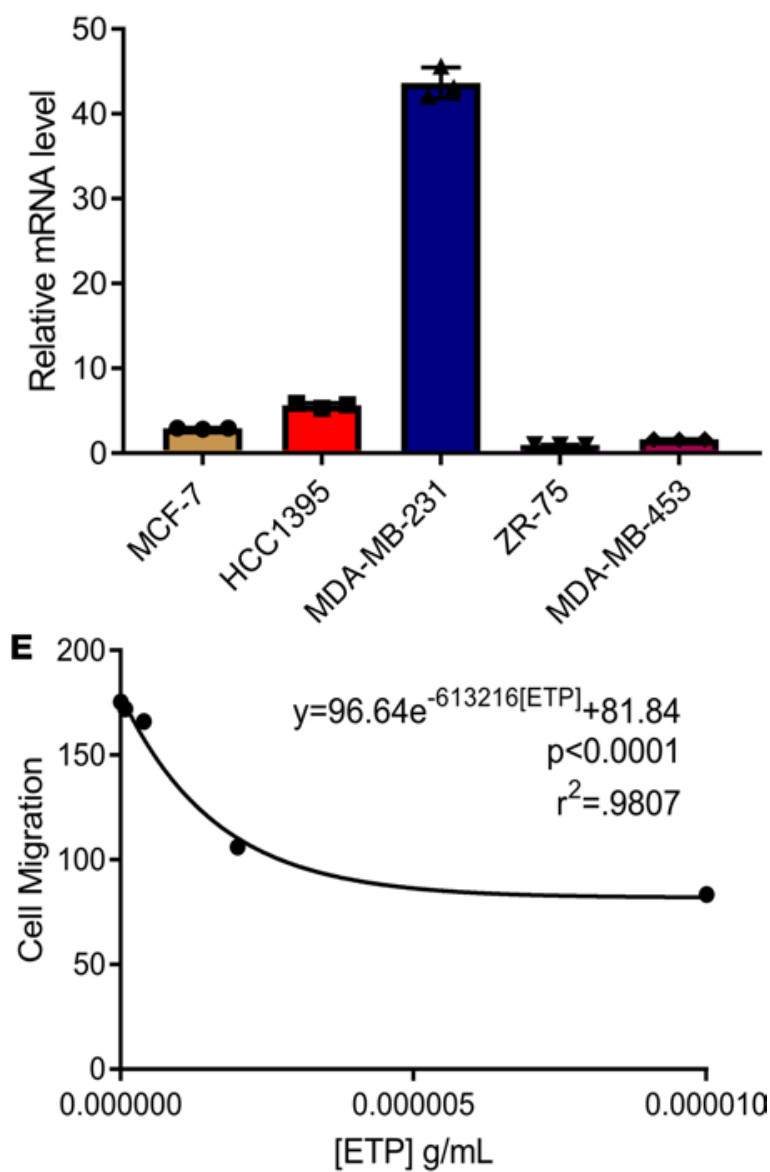

Figure 3. Generation and screening of anti-human endotrophin. (A) MCF-7 breast cancer cells (20,000 cells) were plated into a 96 -well plate. Cells were then treated with $10 \mu \mathrm{m}$ cisplatin, $10 \mu \mathrm{m}$ cisplatin $/ 100 \mathrm{ng} / \mathrm{mL}$ endotrophin, and $10 \mu \mathrm{m}$ cisplatin $/ 100 \mathrm{ng} / \mathrm{mL}$ endotrophin/10 $\mu \mathrm{g} / \mathrm{mL}$ ETPmAb4 for 24 hours. Cell survival was measured using a CellTiter One Solution Cell Proliferation Assay. Statistical significance of the curve fit parameters was tested using the extra sum of squares $F$ test with $P<0.05$ considered significant. Goodness of curve fit is described using $r^{2}$. Mean \pm SEM, $n=3$. (B) ETP transfected MCF-7 cells (100,000 cells) were plated into a 24 -well plate with $500 \mu \mathrm{L}$ media. Then $4 \mu \mathrm{L}$ of supernatant was loaded for Western blotting. It is estimated that approximately $1 \mathrm{ng}$ of ETP was loaded, compared with the standard ETP ( $2 \mathrm{ng}$ band). So the concentration yields approximately $0.052 \mathrm{pg}$ secreted ETP/hr/ cell. (C) Total RNA was extracted from MCF-7, HCC1395, MDA-MB-231, ZR-75-1, and MDA-MB-453 cells. ETP expression was determined by qRT-PCR and normalized to GAPDH. Mean \pm SEM, $n=3$. (D) MCF-7 cells $\left(5 \times 10^{5}\right.$ cells $)$ and ETP-MCF-7 $\left(5 \times 10^{5}\right.$ cells $)$ were harvested and total RNA was extracted. Expression levels of the EMT marker genes Twist, Snail, Cdh2, and Cdh1 were determined by qRT-PCR, then normalized to GAPDH. Mean \pm SEM, $n=3$. (E) ETP transfected MCF-7 cells $\left(1 \times 10^{5}\right.$ cells) were plated at the bottom chamber in a trans-well plate. Then $10 \mu \mathrm{g} / \mathrm{mL}, 2 \mu \mathrm{g} / \mathrm{mL}, 0.4 \mu \mathrm{g} / \mathrm{mL}$, and $0.08 \mu \mathrm{g} / \mathrm{mL}$ ETPmAb4 was added to the bottom on day 2 . SC macrophage cells (50,000 cells) were seeded at the top of the chamber on day 3 . Migrated cells were counted after a 2 hour incubation. Statistical significance of the curve fit parameters was tested using the extra sum of squares $\mathrm{F}$ test with $P<0.05$ considered significant. Goodness of curve fit is described using $r^{2}$. Mean $\pm \mathrm{SEM}, n=3$. In all cases, data was represented as mean $\pm \mathrm{SEM}$, and statistical significance $\left({ }^{* * *} P<0.0001\right)$ was calculated using unpaired, 2-tailed $t$-test w/Holm-Sidak correction for multiple comparisons. 
In vivo effects of endotrophin overexpressing MCF-7 cells. To establish the system in vivo, we compared the relative rate of tumor growth between MCF-7 cells that were stably transfected with a control vector and the MCF-7 clone that was transfected with a plasmid enabling the expression and secretion of endotrophin. Two million cells were injected into the flank of nude mice. Control MCF-7 cells were injected into one side of mice, and MCF-7 cells overexpressing endotrophin were injected into the other side of mice. Lesion growth was subsequently monitored (Figure 4A). MCF-7 cells that overexpress endotrophin showed a significantly faster rate of tumor growth than control cells, further supporting the strong pro-mitogenic effect that endotrophin exerts on tumor cells. MCF-7 tumor lesions with higher levels of endotrophin showed higher vascular density (as judged by the higher density of endomucin staining), an increased rate of tumor-associated macrophage infiltration (as judged by the higher density of Mac2 staining) and a significant reduction of E-cadherin, the latter being consistent with an enhanced progression of the EMT process (Figure 4B). In fact, an analysis of EMT markers shows that the ETP-overexpressing MCF-7 cells in vivo have progressed further through EMT compared to control MCF-7 cells as judged by lower expression of E-cadherin and higher expression of the other EMT markers (Figure 4C).

Use of a novel mass spectroscopy-based methodology to determine the in vivo half-life of the monoclonal anti-endotrophin ETPmAb4. To acquire a better sense of the plasma half-life of ETPmAb4 in vivo, we injected a nude mouse with $200 \mu \mathrm{g}$ of antibody, then utilized a novel state-of-the-art mass spectrometry-based quantitation method to determine the injection schedule for future experiments. The methodology relies on a partial trypsin digest step that generates a unique fingerprint of cleavage products; this consequently allows for the identification of the relative amounts of a unique antibody population amongst plasma, which contains a large number of different endogenous antibodies (nSMOL Shimadzu Corporation Kyoto, Japan). Figure $4 \mathrm{D}$ shows that the half-life of antibody ETPmAb4 in the nude mouse is approximately 5 days.

Anti-endotrophin antibodies significantly curb lesion growth of MCF-7-ETP cells in vivo. As a next step, we examined whether the anti-endotrophin antibodies effectively curb the aggressive tumor growth observed in endotrophin overexpressing MCF-7 cells. To boost the growth rate of the tumor cells, we performed these assays in the presence of estradiol pellets. We injected cells $\left(2 \times 10^{6}\right.$ cells $)$ into nude mice and monitored their tumor growth over time, based on a twice weekly injection of either a control monoclonal preparation, or ETPmAb4; in all cases we utilized a total of $20 \mathrm{mg} / \mathrm{kg}$ of antibody. We tested the dose dependence, by either injecting $20 \mathrm{mg} / \mathrm{kg}$ of control antibody, $20 \mathrm{mg} / \mathrm{kg}$ of ETPmAb4, or a mixture of the two with decreasing levels of control antibody mixed with increasing levels of ETPmAb4. As observed in Figure 5A, the presence of neutralizing endotrophin antibody significantly reduced in a dose-dependent fashion the rate of tumor growth over time; with the highest dose of ETPmAb4 almost completely curbing the aggressive tumor growth observed in the presence of control antibody alone. Representative tumors are shown on the right-hand side. Consistent with this, real-time qPCR analyses revealed a reduced EMT signature, with a significant upregulation in $C d h 1$ (E-cadherin) gene expression levels, with a concomitant downregulation in Cdh2 (N-cadherin), Twist and Snail expression levels (Figure 5B, left). The increased $C d h 1$ (E-cadherin) gene expression levels in the antibody-treated group are also apparent at the protein level, as judged by the markedly enhanced staining intensity with E-cadherin antibodies (Figure 5B, right). Reduced vascular density was observed in the presence of the antibody (Supplemental Figure 5A) along with a reduced presence of tumor-associated macrophages (Supplemental Figure 5B) and additional analysis of E-cadherin (Supplemental Figure 5C). This indicates that neutralization of endotrophin effectively reduces the EMT process, and further suggests that the antibody-treated tumors should be more sensitive to the actions of chemotherapeutic agents.

Anti-endotrophin antibodies significantly enhance the cisplatin susceptibility of MCF-7-ETP cells in vivo. We subsequently probed whether the in vitro findings that suggest enhanced susceptibility to cisplatin upon neutralization of endotrophin, would translate to an in vivo situation. To test this, we utilized MCF-7 cells with or without endotrophin overexpression, and transplanted the cells into nude mice, in the presence of estradiol pellets (Figure 5C). While MCF-7 cells grew effectively under these conditions (Figure 5C; green line), cisplatin significantly curbed lesion growth (Figure 5C; black line). As expected, MCF-7 cells harboring an excess in endotrophin grew very aggressively (Figure 5C; red line). In the presence of cisplatin, or in the presence of cisplatin with control antibody, lesion growth was moderately reduced (Figure 5C; pink and blue lines). In the presence of cisplatin and ETPmAb4 (Figure 5C; orange line), we effectively reduce lesion growth down to essentially baseline; indicating that in the presence of the ETPmAb4, cells become highly susceptible to cisplatin-induced growth arrest. Representative tumors are shown on the right-hand side. 
A

Tumor size

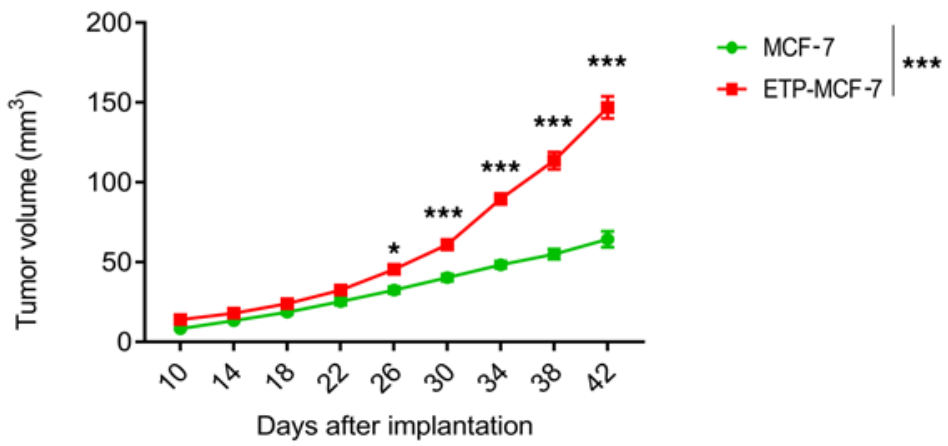

B

HE

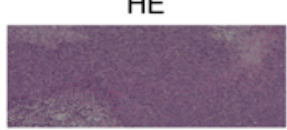

Endomucin
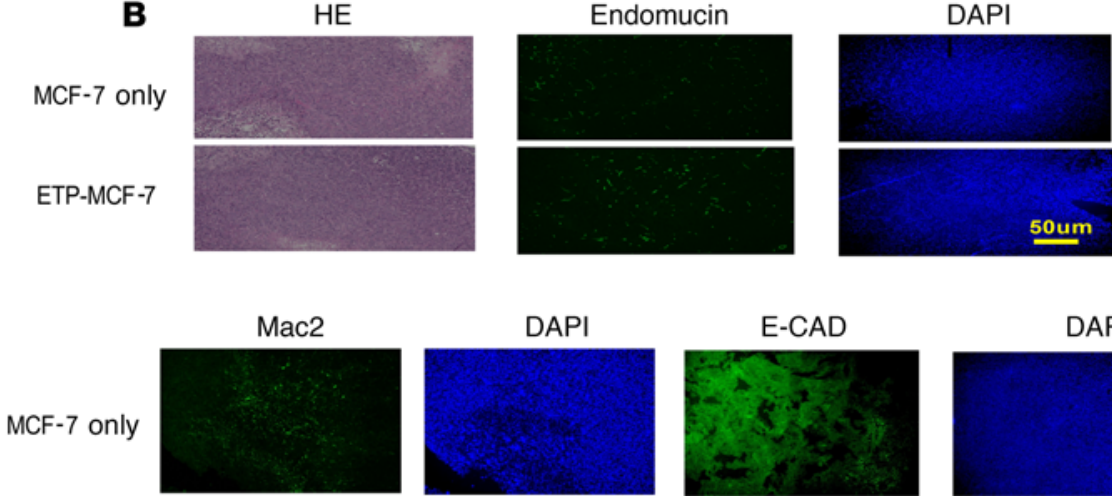

DAPI

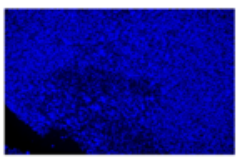

E-CAD
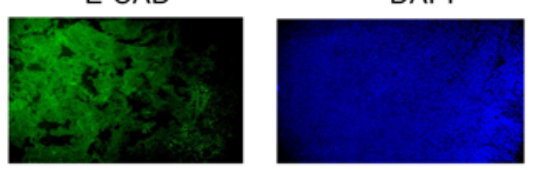

ETP-MCF-7
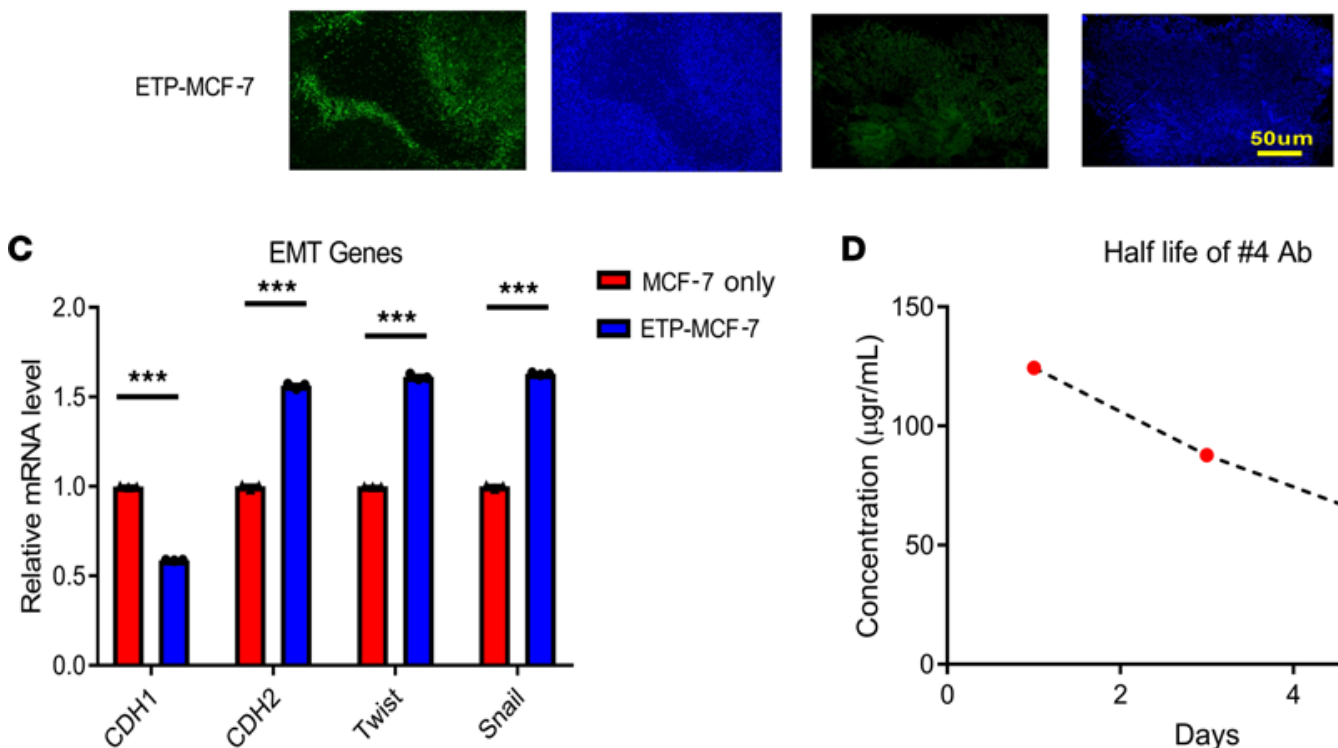

D

Half life of \#4 $\mathrm{Ab}$

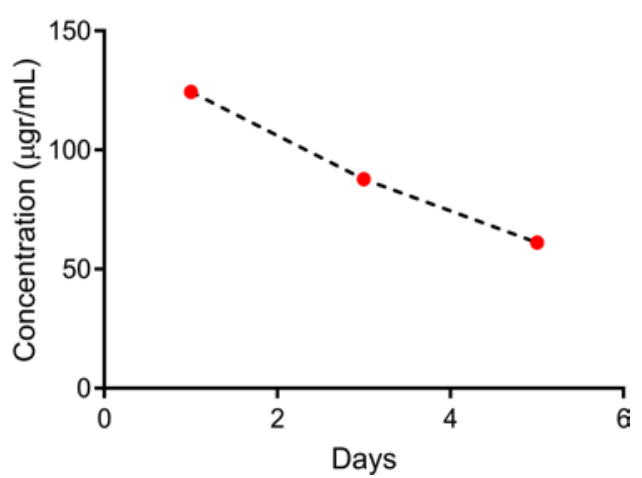

Figure 4. The in vivo effects of endotrophin overexpressing MCF-7 cells. (A) GFP-MCF-7 cells $\left(2 \times 10^{6}\right.$ cells) (control) and ETP transfected MCF-7 cells $\left(2 \times 10^{6}\right.$ cells) were implanted into nude mice for 6 -weeks. Tumor volume was determined by caliper measurement. Data was represented as mean \pm SEM ( $n=8 / \mathrm{group}$ ) and ${ }^{* *} P<0.001,{ }^{* *} P<0.0001$ by calculated by using 2-way ANOVA with Sidak's correction for multiple comparisons. (B) H\&E staining of tumor lesions from MCF-7 and ETP-transfected MCF-7 tumors. Endomucin immunofluorescence staining of tumor tissues from MCF-7 and ETP-transfected MCF-7 tumors. Mac2 immunofluorescence staining for tumor tissues from MCF-7 and ETP- transfected MCF-7 tumors. E-CAD immunofluorescence staining for tumor tissues from MCF-7 and ETP-transfected MCF-7 tumors. Scale bars: $50 \mu \mathrm{m}$. (C) Total RNA was extracted from implanted MCF-7 and ETP-MCF-7 tumors. Expression of the EMT marker genes Twist, Snail, Cdh2, and Cdh1 was determined by qRT-PCR, then normalized to CAPDH. Mean \pm SEM, $n=3$, and statistical significance (*** $P<$ 0.0001) was calculated using unpaired, 2-tailed $t$-test $w / H o l m-S i d a k$ correction for multiple comparisons. (D) Half-life determination of ETPmAb4 in the mouse.

Anti-endotrophin antibodies significantly curb tumor growth and enhance cisplatin susceptibility of MDA-MB-231 cells in vivo, even at later stages of progression. Endotrophin-overexpressing MCF-7 cells serve as an excellent tool to establish the basic parameters of our in vivo experiments. To establish the usefulness of endotrophin inhibition, we wanted to establish that this approach works effectively with tumor cells that express endotrophin 
A

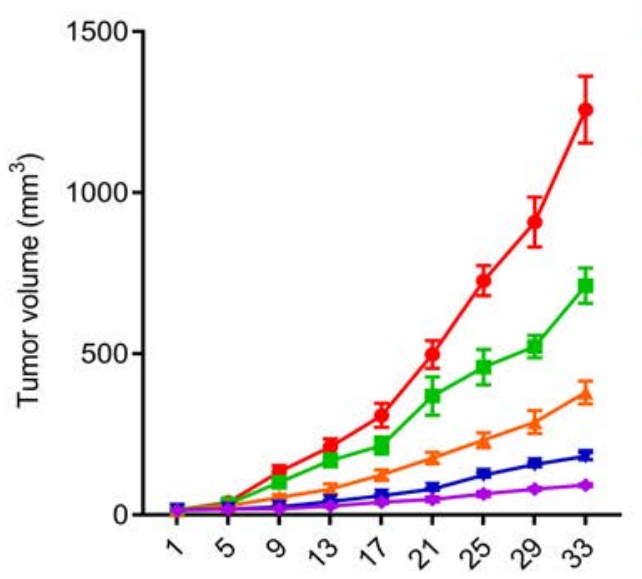

Days after treatment
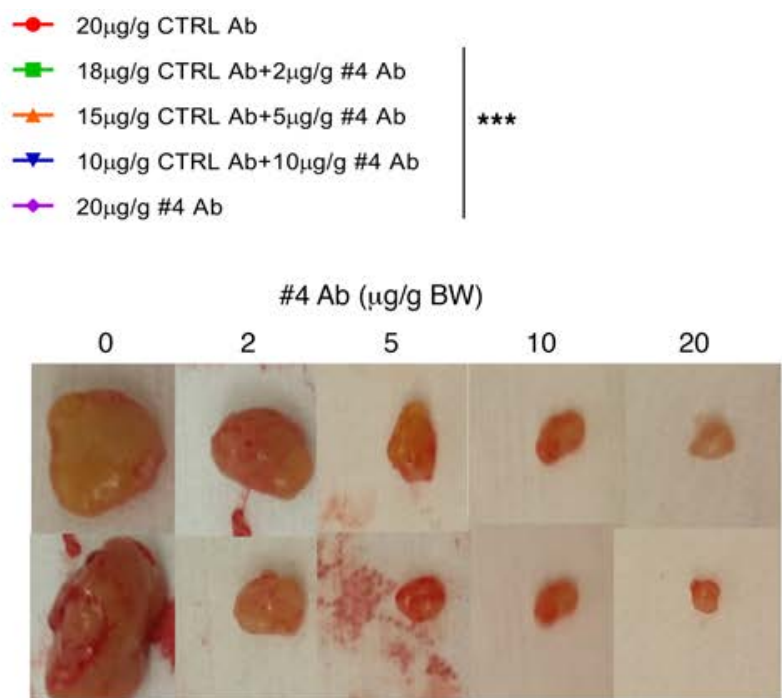

ECAD

B

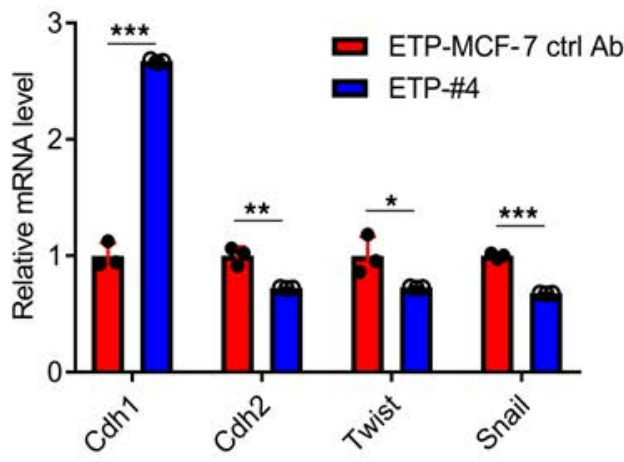

ETP-MCF-7 CTRL Ab

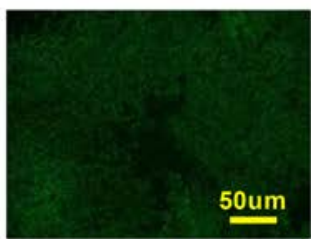

ETP-\#4 Ab
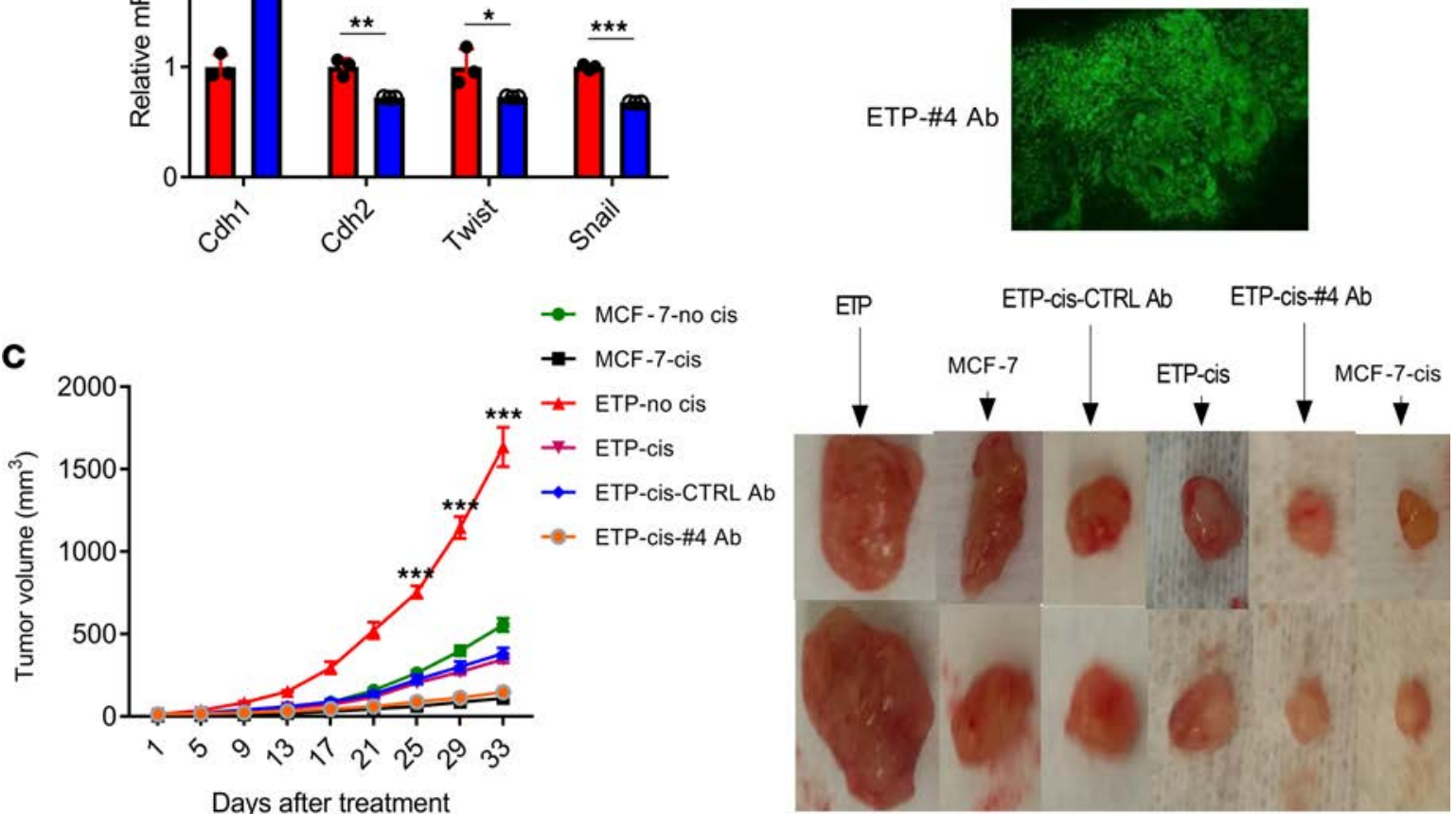

Figure 5. Antibody effects on ETP-MCF-7 cells in vivo. (A) ETP transfected MCF-7 cells $\left(2 \times 10^{6}\right.$ cells) were implanted into nude mice. An estradiol pellet (0.72 mg) was implanted into nude mice. Then (i) $20 \mathrm{mg} / \mathrm{kg}$ ETPmAb4, (ii) $10 \mathrm{mg} / \mathrm{kg}$ ETPmAb4 with $10 \mathrm{mg} / \mathrm{kg}$ control lgG, (iii) $5 \mathrm{mg} / \mathrm{kg}$ ETPmAb4 with 15 $\mathrm{mg} / \mathrm{kg}$ control lgG, (iv) $2 \mathrm{mg} / \mathrm{kg}$ ETPmAb4 with $18 \mathrm{mg} / / \mathrm{kg}$ control lgG, and (v) $20 \mathrm{mg} / \mathrm{kg}$ control lgG (twice a week) were injected after 10-days implantation for 5 -weeks. Tumor volume was determined by caliper measurement. Data was represented as mean \pm SEM $(n=5 /$ group), and *** $P<0.0001$ by 2 -way ANOVA with Sidak's correction for multiple comparisons. Representative tumors shown. (B) Left: Total RNA was prepared from tumor tissues from ETP transfected MCF-7, ETPmAb4 treatment mice. The EMT markers genes Twist, Snail, Cdh2, and Cdh1 were determined by qRT-PCR, then normalized to GAP$\mathrm{DH}$. Mean $\pm \mathrm{SEM}, n=3$. Right: E-CAD immunofluorescence staining for tumor tissues from ETP transfected MCF-7 and ETPmAb4 treatment tumor. Scale bars: $50 \mu \mathrm{m}$. (C) Left: MCF-7 and ETP transfected MCF-7 cells $\left(2 \times 10^{6}\right.$ cells) were implanted into nude mice. An estradiol pellet ( $\left.0.72 \mathrm{mg}\right)$ was implanted into nude mice. Then $20 \mathrm{mg} / \mathrm{kg}$ of antibody ETPmAb4 (twice a week), and $2.5 \mathrm{mg} / \mathrm{kg}$ of cisplatin (once a week) were injected after 10-days implantation for 6 -weeks. Tumor volume was determined by caliper measurement. Right: Representative tumors shown. Data was represented as mean \pm SEM $(n=5 /$ group), and ${ }^{* *} P<0.0001$ by 2 -way ANOVA with Sidak's correction for multiple comparisons. 
A

MDA-MB-231 early stage

ติ

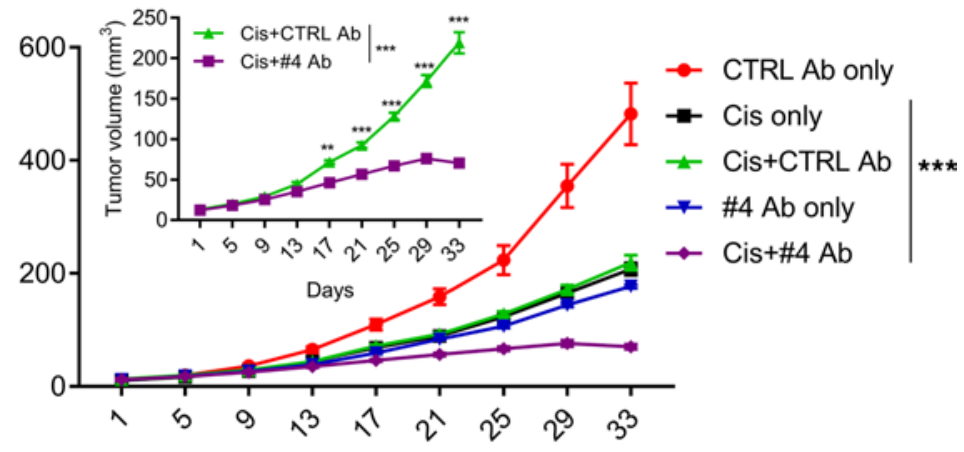

Days after treatment

B

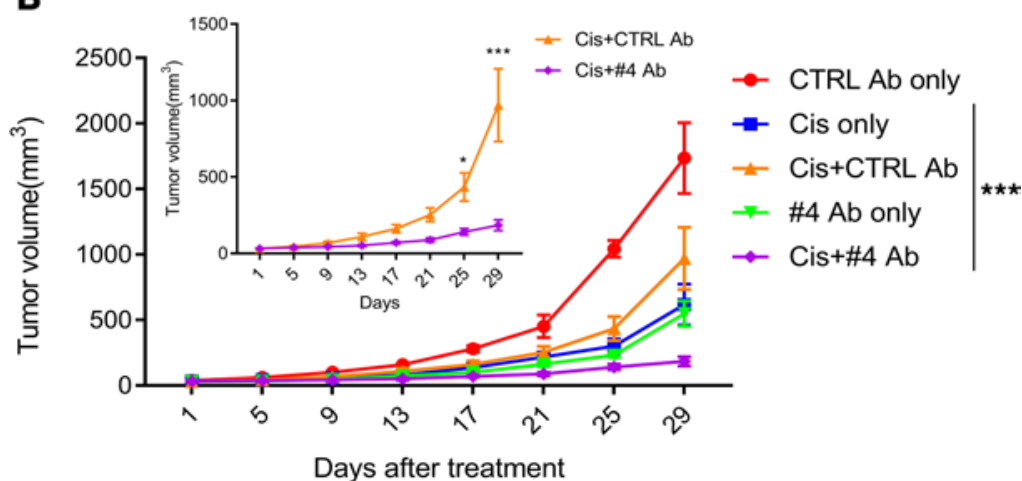

Figure 6. The antibody effects on MDA-MB-231 cells in vivo. (A) MDA-MB- 231 cells $\left(2 \times 10^{6}\right.$ cells) were implanted into nude mice. Then $2.5 \mathrm{mg} / \mathrm{kg}$ of cisplatin and $20 \mathrm{mg} /$ $\mathrm{kg}$ of ETPmAb4 antibody (twice a week) were injected after 10 -days implantation for 5 -weeks. Tumor volume was determined by caliper measurement. The insert reflects a simplified analysis of control antibody versus ETPmAb4 with associated statistics. (B) MDA-MB-231 cells $\left(2 \times 10^{6}\right.$ cells) were implanted into nude mice. Treatment was started when the tumor volume was over $30 \mathrm{~mm}^{3}$. At that point, $2.5 \mathrm{mg} / \mathrm{kg}$ of cisplatin and $20 \mathrm{mg} / \mathrm{kg}$ of ETPmAb4 antibody (twice weekly) were injected for 5 -weeks. Tumor volumes were determined by caliper measurements. The insert reflects a simplified analysis of control antibody versus ETPmAb4 with associated statistics. (c) SKOV3 cells $(2 \times$ $10^{6}$ cells) were implanted into nude mice. Then $2.5 \mathrm{mg} / \mathrm{kg}$ of cisplatin and $20 \mathrm{mg} / \mathrm{kg}$ of ETPmAb4 antibody (twice weekly) were injected 10 -days after implantation for 5 -weeks. Tumor volumes were determined by caliper measurements. The insert reflects a simplified analysis of control antibody versus ETPmAb4 with associated statistics. (D) MDA-MB- 231 cells $\left(2 \times 10^{6}\right.$ cells) were implanted into nude mice. Then $2.5 \mathrm{mg} / \mathrm{kg}$ of cisplatin, $20 \mathrm{mg} / \mathrm{kg}$ of ETPmAb4 antibody and $20 \mathrm{mg} / \mathrm{kg}$ of humanized ETPmAb4 antibody (twice a week) were injected after 10-days implantation for 5-weeks. Tumor volume was determined by caliper measurement. In all case, data was represented as mean \pm SEM ( $n=5$ /group), and ${ }^{* *} P<0.0001$ by 2 -way ANOVA with Sidak's correction for multiple comparisons.

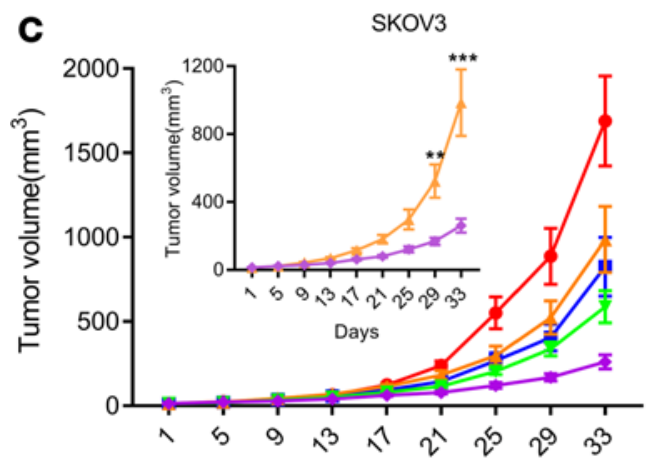

Days after treatment

D

MDA-MB-231

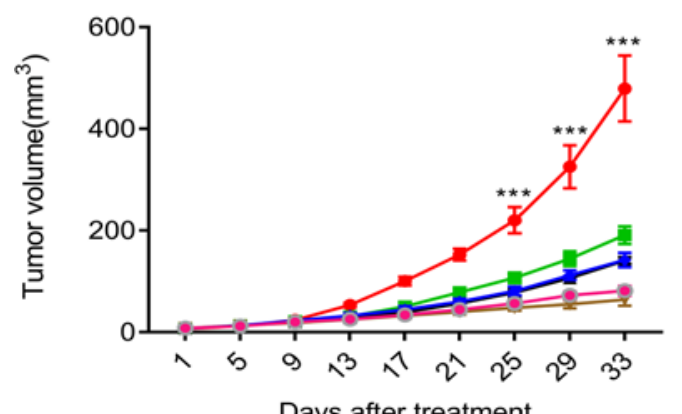

$\rightarrow$ CTRLAb only

- Cis+ CTRL Ab

- \#4 Ab only

$\rightarrow$ Cis $+\# 4 \mathrm{Ab}$

$\rightarrow \mathrm{H \# 4}$ Ab only

$\rightarrow-\mathrm{Cis}+\mathrm{H} \# 4 \mathrm{Ab}$ 
endogenously at significant levels. For this purpose, we decided to utilize the MDA-MB-231 breast cancer cellline (Figure 3C). Injection of these cells into nude mice established an aggressive lesion growth (Figure 6A; red line), which was reduced in the presence of cisplatin, or cisplatin with the control antibodies (20 mg/ $\mathrm{kg})$ (Figure 6A; black and green lines). The mere presence of ETPmAb4 significantly reduced the rate of tumor growth, and the combination of ETPmAb4 with cisplatin, essentially inhibited lesion growth. This underlines the effective anti-mitogenic effects of ETPmAb4, and its ability to render the cells susceptible to cisplatin (Figure 6A; blue and purple lines). The insert reflects a simplified analysis of control antibody versus ETPmAb4 with associated statistics. Again, similar to the observations made with the MCF-7 cells, antibody treatment leads to a reduced vascular density (Supplemental Figure 6A), reduction in tumor-associated macrophages (Supplemental Figure 6B) and enhanced Cdh1 (E-cadherin) protein expression (Supplemental Figure 6C).

To make these observations somewhat more relevant for the clinical setting, we delayed the administration of the antibody until the MDA-MB-231 tumors had reached a minimum size of $30 \mathrm{~mm}^{2}$. As seen in Figure $6 \mathrm{~B}$, antibody treatment alone (green line) or in combination with cisplatin (purple line) proved to be highly effective, even after tumors had progressed quite significantly. The insert reflects a simplified analysis of control antibody versus ETPmAb4 with associated statistics.

Anti-endotrophin antibodies significantly curb tumor growth and enhance cisplatin susceptibility of an ovarian cancer cell line in vivo. As we believe that these findings have broader implications, we also picked the aggressive ovarian cancer cell line SKOV3 and performed comparable experiments and found that the combination of antibody and cisplatin treatment proved to be highly effective in the context of ovarian cancers as well (Figure 6C). The insert reflects a simplified analysis of control antibody versus ETPmAb4 with associated statistics.

$A$ "humanized version" of the anti-endotrophin antibody significantly curbs tumor growth and enhances cisplatin susceptibility of MDA-MB-231 cells in vivo. For potential clinical development, we humanized ETPmAb4 into a human IgG1 subclass and kappa light chain using a CDR grafting strategy and we named the humanized antibody hETPmAb4 $(21,22)$. After humanization, we measured the binding affinity of hETPmAb4 to endotrophin in Octet RED96. The $\mathrm{K}_{\mathrm{d}}$ of $\mathrm{hETPmAb} 4$ binding to endotrophin as measured by Octet RED96 is $1.52 \mathrm{nM}$ which is comparable to the $\mathrm{Kd}$ of $1.62 \mathrm{nM}$ for the parental ETPmAb4 (Supplemental Figure 7). These results suggest that hETPmAb4 maintained the binding affinity of the parental rabbit ETPmAb4. We then repeated the same in vivo experiments that were shown in Figure 6A, with the hETPmAb4. As observed in Figure 6D, the exact same response was observed as in Figure 6A; indicating that the humanization process did not impact the in vivo efficacy of the parental rabbit monoclonal antibody ETPmAb4.

\section{Discussion}

The major aim of our ongoing studies here is to examine whether the basic physiological responses to endotrophin that we previously demonstrated in murine cells are equally preserved in human cells. These actions include pro-fibrotic properties (10), chemoattractant properties for monocytes and macrophages, pro-angiogenic properties, as well as the ability to induce chemoresistance due to enhanced epithelial-mesenchymal transition (EMT) $(6,12)$. The ultimate goal was to develop and validate a neutralizing antibody against human endotrophin, which could ultimately acquire clinical application. Here, we effectively established that the hallmark effects of endotrophin are fully preserved between mouse and human.

We firstly report the potent chemoattractant properties of human endotrophin in macrophages. Furthermore, by utilizing scratch assays, we demonstrate that endotrophin acts on endothelial cells (HUVECs) to enhance their overall migration behavior. Endotrophin can therefore function as a chemoattractant for HUVECs, and also potently stimulate tube formation, as a reflection of its pro-angiogenic potential. Finally, we show that endotrophin acts as a potential stimulator of the EMT, which inflicts several changes to cells, including the induction of specific EMT markers, and cisplatin resistance. All our in vitro assays were employed to functionally test the efficacy of a battery of novel endotrophin neutralizing antibodies, which effectively reduced the efficacy of endotrophin to cause these actions upon exposure to fat cells. When taken in vivo, endotrophin neutralization effectively curbed lesion growth, and moreover, rendered tumors susceptible to the effects of cisplatin.

Even though we believe that the role of endotrophin is predominantly paracrine in nature, acting primarily within the microenvironment, we also postulate that a proportion of the protein escapes from the local tissue and can be identified in circulation. Here, we report the elevated circulating levels of endotrophin in the plasma of breast cancer patients. As such, future studies will have to demonstrate whether we can identify higher levels of endotrophin in circulation in the context of other cancers too, such as hepatocellular carcinoma, colon cancer, ovarian and endometrial cancer. These are all circumstances under 
which we observe an increase in endotrophin production within the tumor, or the surrounding fat tissue. Furthermore, it will be interesting to see how early elevated endotrophin levels can be detected during tumor progression, i.e. can endotrophin be utilized as an early detection tumor marker, or is it merely a reflection of progressed tumor mass?

Several recent papers have reported the plasma measurement of endotrophin in human samples, though primarily in the context of metabolic diseases. Rasmussen and colleagues (23) focused on individuals with chronic kidney disease and found that urinary endotrophin predicts disease progression. They followed up on these observations and demonstrated that higher levels of an endotrophin-containing fragment are associated with all-cause mortality in patients with type 2 diabetes and microalbuminuria (24). Similarly, Fenton and colleagues (25) reported that an increase in serum endotrophin is associated with increased mortality in chronic kidney disease. Karsdal and colleagues (26) further utilized baseline serum endotrophin levels in type 2 diabetic patients to predict which individual would respond most effectively to insulin-sensitizing PPAR $\gamma$-agonist treatment. The latter set of observations has to be understood in the context of the reciprocal relationship between PPAR $\gamma$ activity and expression of the endotrophin precursor, collagen VI $\alpha 3$ (9). Treatment with thiazolidinediones (TZDs), which are PPAR $\gamma$ agonists, effectively suppress collagen VI $\alpha 3$ transcription, as part of its generalized anti-fibrotic properties (27). We have previously shown that treatment with TZDs, in the context of a mammary tumor model, further enhances cisplatin susceptibility of mammary tumors (12), at least partially reproducing the results reported here with the neutralizing antibody. This suggests that co-administration of the neutralizing antibody with TZDs may also further enhance the susceptibility of tumor cells to cisplatin.

For these reasons, we will need to consider in the future, the use of endotrophin neutralization as an anti-fibrotic approach as well. In high-fat diet-fed mice, we have already demonstrated that treatment with a neutralizing antibody to mouse endotrophin, reduces fibrosis in adipose tissue and leads to an improvement in insulin sensitivity (10). More importantly, both the kidney, the liver and bone marrow are organs of interest with major pathologies associated with chronic pro-fibrotic responses, including an upregulation in endotrophin. Future studies will have to examine the effectiveness of neutralizing endotrophin in the context of diabetic nephropathy and fatty liver disease progression, ultimately leading to hepatocellular carcinoma. As such, these neutralizing antibodies may find important use in fibrotic diseases, as well as in the context of a host of additional tumor settings associated with an upregulation of collagen VI in general, and endotrophin specifically.

\section{Methods}

Animal experiments. NU/NU nude female mice were purchased from Charles River (Crl:NU-Foxn1nu; Strain Code 088 [Homozygous]). Breast cancer cells $\left(2 \times 10^{6}\right.$ cells) were implanted by intraductal injection. All cell lines were mixed on ice with 1X PBS and Matrigel. Then $100 \mu \mathrm{L}$ of mixture was injected into mice. Tumors were measured twice a week, beginning 10 days after injection, and tumor volume was calculated by length $\times(\text { width })^{2} / 2\left(\mathrm{~mm}^{3}\right)$.

Recombinant endotrophin expression in HEK293 cells. To generate bioactive human endotropin for in vitro and in vivo studies and to generate neutralizing antibodies against human endotrophin, a strategy to express human endotrophin in HEK293 cells was designed (Sino Biological). Briefly, the construct includes a CD33 signal peptide, followed by a His-tag, an EK-cleavage site and the predicted human endotrophin sequence; the latter consisting of 77 amino acids at the carboxy-terminal of the COL6 33 chain. After purification of the protein using a nickel column, the His-tag was removed by enterokinase cleavage, which results in the 77 amino-acid human endotrophin free of tags.

Endotrophin-specific polyclonal and monoclonal antibodies. Rabbits (NZW) were immunized with recombinantly-produced human endotrophin protein (Sino Biological), using a standard immunization procedure (RevMab Biosciences). After 4 boosts, blood (30-40 ml/rabbit) was sampled for memory B cell isolation, using an IgG+ Memory B Cell Isolation Kit (Miltenyi Biotec). After culturing individual B cells for 14 days, supernatants were tested for antibody specificity to endotrophin by ELISA. Variable gene fragments encoding the endotrophin-specific antibodies were cloned using a set of rabbit antibody gene specific primers, as described previously (28). Full-length antibodies were constructed and expressed using a mammalian expression vector system in HEK293 suspension cells (Invitrogen) (29). Antibodies were purified using a Protein A affinity resin, and the purity was confirmed on a SDS-PAGE gel. Rabbit sera were collected from blood samples for isolation of polyclonal anti-endotrophin antibodies that were used for setting up ELISA detection of circulating endotrophin in patient plasma samples. 
ELISA based measurements of circulating endotrophin. Plasma samples $(n=195)$ were collected from breast cancer patients with informed consent under the approved Institutional Review Board protocols \# HSCMS-10- 0580 and HSC-MS-11-0559 at the University of Texas McGovern Medical School at Houston (30). Plasma samples $(10 \mathrm{~mL})$ were freshly prepared from blood samples collected before surgery and were preserved at $-80^{\circ} \mathrm{C}$ until analysis. Plasma samples from normal donors $(n=40)$ were obtained from an outside vendor (Cureline Inc). To quantitatively determine the levels of circulating endotrophin in human plasma collected from breast cancer patients, 96-well maxi-sorp plates (Corning Costar) were coated with rabbit polyclonal anti-endotrophin antibodies prepared in house at $20 \mu \mathrm{g} / \mathrm{mL}$ concentration. Plasma samples were titrated at a series of dilutions in 1 X PBS, then added to an anti-endotrophin coated plate. A high affinity specific anti-endotrophin antibody (ETPmAb4) was biotinylated using an amine conjugation kit (Fisher Scientific), then utilized as secondary detection antibody. Streptavidin conjugated with HRP (horseradish peroxidase) (Fisher Scientific) was used for detection of endotrophin signals, using the dilution as suggested by the manufacturer. A purified endotrophin recombinant protein was titrated in a series of concentrations $(0-5000 \mathrm{pg} / \mathrm{mL})$ to establish a standard curve for calculation of endotrophin in plasma samples.

MTS assay screening endotrophin monoclonal antibodies. MCF-7 breast cancer cells (20,000 cells) were plated into a 96-well plate. Cells were then treated with $10 \mu \mathrm{M}$ of cisplatin and $100 \mathrm{ng} / \mathrm{mL}$ of endotrophin. In total, 132 neutralized endotrophin antibodies were screened. Cell survival was measured using a CellTiter One Solution Cell Proliferation Assay. CellTiter One Solution Reagent $(20 \mu \mathrm{L})$ was added into each well of 96-well plate, and incubated at $37^{\circ} \mathrm{C}$ for 4 hours. The plate was then read at $490 \mathrm{~nm}$ using a Sunrise microplate reader (TECAN).

Immunoprecipitation of human endotrophin. The monoclonal anti-human endotrophin antibody \#4 was covalently immobilized to SulfoLink Coupling Resin (ThermoFisher) per manufacturer's instructions. Briefly, endotrophin antibody was incubated with TCEP (ThermoFisher) for 1 hour to reduce the available sulfhydryl bonds in coupling buffer (50 mM Tris, $5 \mathrm{mM}$ EDTA; pH 8.5). The reduced antibody was incubated with SulfoLink coupling resin in a gravity-flow column for 1 hour. The column was then washed with coupling buffer, quenched with L-cysteine- $\mathrm{HCl}$ and washed with $1 \mathrm{M} \mathrm{NaCl}$. Following equilibration with $1 \mathrm{X}$ PBS, 2 $\mathrm{mL}$ of human plasma was passed through the affinity column twice. Un-bound proteins were washed off the column with $1 \mathrm{X}$ PBS and the captured endotrophin was eluted with $0.2 \mathrm{M}$ glycine, $\mathrm{pH}$ 2.5. Western blotting was performed with a purified rabbit polyclonal antibody raised against a GST-fusion protein (GST-hETP containing glutathione S-transferase and the carboxy-terminal amino acids 3101 3177 of human Col6 3 ).

Expression analysis in human breast cancer tumors. Col6a 3 mRNA expression in matched control healthy tissue and tumor tissue from 111 breast cancer patients were downloaded and extracted from data generated by the TCGA Research Network: http://cancergenome.nih.gov/. The data was analyzed and statistical significance was determined using the deseq2 package, using R (https://doi.org/10.1186/s13059.014.0550-8).

Disease specific survival analysis. Probe-level mRNA expression values of Col6a3 determined by the IlluminaBead platform were obtained from tumor lesions from 203 breast cancer patients with stage 3 tumors (http://journals.plos.org/plosone/article?id=10.1371/journal.pone.0019249\#s2). Tumor tissue was obtained prior to the initiation of chemotherapy. Each sample was classified as Col6a3-high if the signal was above the median expression for the population (31). Kaplan-Meier curves were generated using GraphPad Prism 7. $P$-value was determined using the log-rank test and Cox proportional hazard models analysis was used to calculate hazard ratios.

Quantitative RT-PCR. Total RNA was isolated using an RNeasy kit (Qiagen) following tissue homogenization in Trizol (Invitrogen). Total RNA $(1 \mu \mathrm{g})$ was reverse transcribed with SuperScript III reverse transcriptase (Invitrogen). Quantitative real-time PCR (qRT-PCR) was performed using a Roche Lightcycler 480. The results were calculated using the $\Delta \Delta \mathrm{C}_{\mathrm{t}}$ method using GAPDH for normalization. Primer sequences used in this study are as detailed in (32).

Analysis of anti-endotrophin antibody half life. The concentration of ETPmAb4 in mouse serum samples was determined using a commercially readily available nSMOL kit (nano-surface and molecular orientation limited proteolysis, Shimadzu Corporation) (33), in combination with liquid chromatography tandem mass spectrometry technology (Nexera X2 UHPLC coupled to LCMS-8060 triple quadrupole mass spectrometer, Shimadzu Scientific Instruments). Commercial human plasma ( $5 \mu \mathrm{L})$ (spiked at known concentrations of ETPmAb4) were then used to generate calibration curves, and a ProteoMass $\mathrm{P}_{14}$ commercial peptide standard (Millipore Sigma) was used as an internal standard. Mouse serum $(5 \mu \mathrm{L})$ from treated mice was employed for analysis.

Immunofluorescence staining. Formalin-fixed paraffin-embedded tissue sections were used for immunofluorescence. De-paraffinized tissue slides were blocked in PBS-Tween with 5\% BSA. Primary antibodies 
used were Endomucin, Mac2 and ECAD (1:200 dilution). Secondary antibodies (1:500 dilution) used were the Alexa Fluor 488 donkey anti-rabbit $\operatorname{IgG}(\mathrm{H}+\mathrm{L})$ preparation. Fluorescence images were acquired on an Olympus FSX100 all-in-one microscope.

Analysis of tumor progression. Tumor onset was monitored twice weekly by palpation. Tumor sizes were measured using a digital caliper twice weekly and the volumes were calculated as length $\times$ width $\left.^{2}\right) / 2$. Inguinal tumors were weighted to determine tumor burden. Animals were sacrificed when the tumor burden visibly affected the host, or when the tumors reached the IACUC pre-determined limit of $20 \mathrm{~mm}$ along one axis.

Primary culture of human cells and transwell assays. SC macrophage cells were seeded at the top of the chamber of a trans-well plate ( $8 \mu \mathrm{m}$ pore size; Costar). Endotrophin or ETP-MCF-7 cells were added into the lower chamber and incubated for 2 hours. Migrated cells were then counted after 2 hours.

Isolation of primary human mesothelial cells. The mesothelial cell population was prepared from omental adipose tissue obtained from adult patients undergoing a bariatric procedure (University of Texas Southwestern Medical Center Institutional Review Board approved this study). The tissue was minimally digested with $0.25 \%$ trypsin for 20 minutes at $37^{\circ} \mathrm{C}$ on a rotating stand. The undigested adipose tissue was removed and the remaining trypsin and cells were centrifuged at $600 \mathrm{~g}$ for $5 \mathrm{~min}$ at $4^{\circ} \mathrm{C}$. The upper layer was discarded and the pellet was resuspended in Media 199 supplemented with $5 \%$ fetal bovine serum (FBS), plated on a 12-well collagen coated plate and grown to confluency (1-2 weeks). When the mesothelial cells reached confluency they were uniformly cobblestone in appearance.

In vitro cell migration assay. HUVECs were seeded at the top of the chamber in a trans-well plate. Endotrophin was added to the bottom chamber with $1 \%$ FBS. After 16 hours, cells on the underside of the membrane were fixed with $10 \%$ formalin and counted. Images were acquired using a Nikon Cool Scope (Nikon).

In vitro tube formation assay. HUVEC cells (40,000 cells) were plated into gel-coated 24 -well plate. Cells were then treated with endotrophin with or without 1\% FBS for 16 hours. A cell-permeable dye (Calcein) was added for fluorescent monitoring of tube formation. Images were then obtained on the Nikon Cool Scope (Nikon) microscope following a 16 hours incubation.

Antibody-antigen ELISA binding assay. Corning 96-well EIA/RIA plates were coated overnight at $4^{\circ} \mathrm{C}$ with HEK293 expressed recombinant endotrpophin $(1 \mu \mathrm{g} / \mathrm{mL})$ and blocked for 2 hours at $37^{\circ} \mathrm{C}$ with $5 \%$ non-fat milk. After washing with PBST for 3 times, $100 \mu \mathrm{L}$ of serial diluted anti-entrophin antibodies were added and incubated for 45 minutes at $37^{\circ} \mathrm{C}$. Subsequently, the plates were washed with PBST and incubated for 30 minutes with anti-rabbit or anti-human F(ab')2 HRP-conjugated antibody (Jackson ImmunoResearch Laboratories). The immunoreactions was developed with TMB substrates (Sigma) and stopped by the addition of $2 \mathrm{M}$ sulfuric acid before reading the plate at $450 \mathrm{~nm}$.

Humanization of rabbit $m A b$. Humanization of the rabbit anti-endotrophin antibody was based a CDR-grafting strategy as described previously (22). Briefly, CDRs in the heavy and light chains of the rabbit antibody were defined by combination of three methods: Kabat, IMGT and Paratome. The parental rabbit $\mathrm{mAb}$ and the most closely related human germline sequence were then aligned. Residues which are known not to be structurally critical and/or subjected to change during the in vivo maturation process were identified in the MLG analysis and humanized. DNA encoding humanized VK and VH were synthesized (GenScript). The human IgG signal peptides and a Kozak sequence were engineered at the 5 ends of the VK and VH sequences. The humanized VK and VH fragments were then cloned into human IgG1 CK and $\mathrm{CH}$ vectors separately. Expression, purification and quantification of the humanized $\mathrm{mAbs}$ are the same as those for rabbit mAbs.

Affinity measurement with BLI. For antibody affinity measurement, anti-endotrophin antibody $(20 \mu \mathrm{g} / \mathrm{mL})$ was loaded onto the protein $\mathrm{G}$ biosensors for 4 minutes. Following a short baseline in kinetics buffer, the loaded biosensors were exposed to a series of recombinant endotrophin protein (0.1-100 $\mathrm{nM}$ ) and background subtraction was used to correct for sensor drifting. All experiments were performed with shaking at 1,000 $\mathrm{rpm}$. Background wavelength shifts were measured from reference biosensors that were loaded only with antibody. ForteBio's data analysis software was used to fit the data to a 1:1 binding model to extract an association rate and dissociation rate. The $\mathrm{K}_{\mathrm{D}}$ was calculated using the ratio $\mathrm{k}_{\mathrm{off}} / \mathrm{k}_{\text {on }}(34)$.

Cell lines, culture, and reagents. The human peripheral monocyte/macrophage cell line SC was obtained from ATTC (SC (ATCC CRL-9855). All breast cancer cell lines (T47D, MCF-7, HCC1395, MDA-MB-231, ZR-75-1, and MDA-MB-453) as well as the ovarian cancer cell line SKOV3 used in this study were obtained from the Hamon Cancer Center Collection (University of Texas Southwestern Medical Center). Cells were maintained in RPMI-1640 supplemented with penicillin-streptomycin and 5\% FBS. HUVEC cells were 
obtained from Lonza and were maintained in EBM medium (Lonza, cc-3121). Cisplatin was obtained from Sigma-Aldrich (479306-1G). Estradiol pellets were acquired from Innovative Research of America (SE-121). Calcein was obtained from Invitrogen (C3099). Geltrex was obtained from ThermoFisher Scientific (A14132-02). CellTiter One Solution Cell Proliferation Assay was acquired from Promega (G3580). The primary antibodies used for histological analyses were as follows: E-cadherin (Novus Biologicals, \#NB110-56937), endomucin (Santa Cruz Biotechnology, \#SC-65495) and Mac2 (Biolegend, \#125401).

Immunoblotting. Cell lysates were harvested using NP-40 lysis buffer, supplemented with phenylmethylsulfonyl fluoride (PMSF, $1 \mathrm{mM}$ ), protease inhibitor (Roche) and phosphatase inhibitor (Roche). Protein samples were immunoblotted using standard methods. For culture media, differentiated 3T3-L1 adipocytes and preadipocytes were serum starved in DMEM media. Following an overnight incubation, the media was harvested and filtered (Millipore, $0.45 \mathrm{~mm}$ ). Conditioned media was then concentrated using centrifugal filters (Amicon Ultra, 3K) at 14,000 $\mathrm{g}$ for 40 minutes. Secreted ETP was detected using $\alpha$-mouse ETP polyclonal antibody, compared to COL6 (Abcam, Ab6588). The primary antibodies were detected with secondary IgG-labeled with infrared dyes emitting at 700 and $800 \mathrm{~nm}$ and visualized on the Licor Odessey Infrared Scanner. The scanned results were analyzed using the Odessey v2.1 software (Licor Bioscience).

Statistics. Data are presented as mean \pm SEM. Graphpad Prism 8.0 (GraphPad Software Inc.) was used to perform statistical analyses. For comparisons between 2 independent groups, Students $t$-test was used with $P$ $<0.05$ considered a statistically significant change (after adjusting for multiple comparisons as appropriate) For longitudinal tumor growth studies, effect of treatments was tested using 2-way ANOVA with Sidak's correction for multiple comparisons. When testing the effect of endotrophin over a range of concentrations, least-squares non-linear regression was used to model the effect of endotrophin. Statistical significance of the fit parameters was determined using the extra sum of squares $\mathrm{F}$ test and goodness of fit described using $\mathrm{r}^{2}$.

Study approval. This study was carried out in strict accordance with the recommendations in the Guide for the Care and Use of Laboratory Animals of the National Institutes of Health. All animal experiments were approved by the Institutional Animal Care and Research Advisory Committee at The University of Texas Southwestern Medical Center (Protocol Number 2015-101207-G).

\section{Author contributions}

$\mathrm{DB}, \mathrm{CC}, \mathrm{HD}$, and WX conducted experiments. RG performed all work related to mass spectrometry analysis. XZL, PEL, NZ, and NH were involved in analysis of clinical results. NZ, AR, JP, and YC conceptualized some of the experiments and helped in analysis and interpretation. WX, HD, NZ, and ZA generated and characterized monoclonal antibodies. MK generated stable cell lines. AG, NZ, and ZA had the clinical protocol for collecting plasma samples from breast cancer patients. CMK, ZA, NZ, and PES wrote the manuscript and conceptualized most experiments.

\section{Acknowledgments}

We would like to thank John Sheldon and his team at the UT Southwestern Medical Center for his help with the histological analyses. We thank the Cancer Prevention and Research Institute of Texas (PR150551), the Robert A. Welch Foundation (I-1834 and AU-0042-20030616), the Korea Health Technology R\&D Project (KHIDI, HI14C1277) and PanaMab for generous support. Furthermore, we would like to thank Tairo Ogura, Bob English, Benjamin J. Figard, Christopher Gilles (Shimadzu Scientific Instruments, Columbia, MD) and Tosiya Matsubara (Shimadzu Corporation, Kyoto, Japan) for technical assistance and the collaborative efforts.

Address correspondence to: Zhiqiang An, Texas Therapeutics Institute, Brown Foundation Institute of Molecular Medicine, University of Texas Health Science Center at Houston, 1825 Pressler Street, Houston, Texas 77030, USA. Phone: 713.500.3011; Email: Zhiqiang.An@uth.tmc.edu. Or to: Philipp E. Scherer, Touchstone Diabetes Center, Department of Internal Medicine, University of Texas Southwestern Medical Center, 5323 Harry Hines Boulevard, Dallas, Texas 75390-8549, USA. Phone: 214.648.8715; Email: Philipp.Scherer@utsouthwestern.edu.

1. Park J, Morley TS, Kim M, Clegg DJ, Scherer PE. Obesity and cancer - mechanisms underlying tumour progression and recurrence. Nat Rev Endocrinol. 2014;10(8):455-465.

2. Calle EE, Rodriguez C, Walker-Thurmond K, Thun MJ. Overweight, obesity, and mortality from cancer in a prospectively studied cohort of U.S. adults. N Engl J Med. 2003;348(17):1625-1638. 
3. Iyengar P, et al. Adipocyte-derived collagen VI affects early mammary tumor progression in vivo, demonstrating a critical interaction in the tumor/stroma microenvironment. J Clin Invest. 2005;115(5):1163-1176.

4. Iyengar $\mathrm{P}$, et al. Adipocyte-secreted factors synergistically promote mammary tumorigenesis through induction of anti-apoptotic transcriptional programs and proto-oncogene stabilization. Oncogene. 2003;22(41):6408-6423.

5. Park J, Scherer PE. Endotrophin — a novel factor linking obesity with aggressive tumor growth. Oncotarget. 2012;3(12):1487-1488.

6. Park J, Scherer PE. Adipocyte-derived endotrophin promotes malignant tumor progression. J Clin Invest. 2012;122(11):4243-4256.

7. Park J, Scherer PE. Endotrophin in the tumor stroma: a new therapeutic target for breast cancer? Expert Rev Anticancer Ther. 2013;13(2):111-113.

8. Park J, Morley TS, Scherer PE. Inhibition of endotrophin, a cleavage product of collagen VI, confers cisplatin sensitivity to tumours. EMBO Mol Med. 2013;5(6):935-948.

9. Sun K, Park J, Kim M, Scherer PE. Endotrophin, a multifaceted player in metabolic dysregulation and cancer progression, is a predictive biomarker for the response to PPAR $\gamma$ agonist treatment. Diabetologia. 2017;60(1):24-29.

10. Sun K, et al. Endotrophin triggers adipose tissue fibrosis and metabolic dysfunction. Nat Commun. 2014;5:3485.

11. Keydar I, et al. Establishment and characterization of a cell line of human breast carcinoma origin. Eur J Cancer. 1979;15(5):659-670.

12. Park J, Morley TS, Scherer PE. Inhibition of endotrophin, a cleavage product of collagen VI, confers cisplatin sensitivity to tumours. EMBO Mol Med. 2013;5(6):935-948.

13. Sciacovelli M, Frezza C. Metabolic reprogramming and epithelial-to-mesenchymal transition in cancer. FEBS J. 2017;284(19):3132-3144.

14. Gupta OT, Gupta RK. Visceral adipose tissue mesothelial cells: living on the edge or just taking up space? Trends Endocrinol Metab. 2015;26(10):515-523.

15. Galdal KS, Evensen SA, Høglund AS, Nilsen E. Actin pools and actin microfilament organization in cultured human endothelial cells after exposure to thrombin. Br J Haematol. 1984;58(4):617-625.

16. Herren B, Raines EW, Ross R. Expression of a disintegrin-like protein in cultured human vascular cells and in vivo. FASEB J. 1997;11(2):173-180.

17. Sakata Y, Okada M, Noro A, Matsuda M. Interaction of tissue-type plasminogen activator and plasminogen activator inhibitor 1 on the surface of endothelial cells. J Biol Chem. 1988;263(4):1960-1969.

18. Maheshwari RK, Srikantan V, Bhartiya D, Kleinman HK, Grant DS. Differential effects of interferon gamma and alpha on in vitro model of angiogenesis. J Cell Physiol. 1991;146(1):164-169.

19. Treves AJ. Human monocytes and macrophages: establishment and analysis of cloned populations and functional cell lines. Crit Rev Immunol. 1985;5(4):371-385.

20. Soule HD, Vazguez J, Long A, Albert S, Brennan M. A human cell line from a pleural effusion derived from a breast carcinoma J Natl Cancer Inst. 1973;51(5):1409-1416.

21. Zhang YF, Ho M. Humanization of rabbit monoclonal antibodies via grafting combined Kabat/IMGT/Paratome complementarity-determining regions: Rationale and examples. MAbs. 2017;9(3):419-429.

22. Yu Y, et al. A humanized anti-VEGF rabbit monoclonal antibody inhibits angiogenesis and blocks tumor growth in xenograft models. PLoS One. 2010;5(2):e9072.

23. Rasmussen DGK, et al. Urinary endotrophin predicts disease progression in patients with chronic kidney disease. Sci Rep. 2017;7(1):17328.

24. Rasmussen DGK, et al. Higher Collagen VI formation is associated with all-cause mortality in patients with type 2 diabetes and microalbuminuria. Diabetes Care. 2018;41(7):1493-1500.

25. Fenton A, et al. Serum endotrophin, a type VI collagen cleavage product, is associated with increased mortality in chronic kidney disease. PLoS One. 2017;12(4):e0175200.

26. Karsdal MA, et al. Serum endotrophin identifies optimal responders to PPAR $\gamma$ agonists in type 2 diabetes. Diabetologia. 2017;60(1):50-59.

27. Khan T, et al. Metabolic dysregulation and adipose tissue fibrosis: role of collagen VI. Mol Cell Biol. 2009;29(6):1575-1591.

28. Freed DC, et al. Pentameric complex of viral glycoprotein $\mathrm{H}$ is the primary target for potent neutralization by a human cytomegalovirus vaccine. Proc Natl Acad Sci U S A. 2013;110(51):E4997-E5005.

29. Fan X, et al. A single proteolytic cleavage within the lower hinge of trastuzumab reduces immune effector function and in vivo efficacy. Breast Cancer Res. 2012;14(4):R116.

30. Zhang N, et al. Dysfunctional antibodies in the tumor microenvironment associate with impaired anticancer immunity. Clin Cancer Res. 2015;21(23):5380-5390.

31. Chrisanthar R, et al. Predictive and prognostic impact of TP53 mutations and MDM2 promoter genotype in primary breast cancer patients treated with epirubicin or paclitaxel. PLoS One. 2011;6(4):e19249.

32. Rosivatz E, et al. Differential expression of the epithelial-mesenchymal transition regulators snail, SIP1, and twist in gastric cancer. Am J Pathol. 2002;161(5):1881-1891.

33. Iwamoto $\mathrm{N}$, et al. Selective detection of complementarity-determining regions of monoclonal antibody by limiting protease access to the substrate: nano-surface and molecular-orientation limited proteolysis. Analyst. 2014;139(3):576-580.

34. Yang D, Singh A, Wu H, Kroe-Barrett R. Comparison of biosensor platforms in the evaluation of high affinity antibody-antigen binding kinetics. Anal Biochem. 2016;508:78-96. 